Economía, Sociedad y Territorio, vol. vi, núm. 24, 2007, 1025-1069

\title{
La identidad colectiva en el sur de Jalisco
}

\author{
Alejandro Macías-Macías*
}

\section{Resumen}

El sur de Jalisco es una región rica en expresiones culturales representativas de las identidades de sus pueblos. Sin embargo, en este trabajo sostengo que en términos regionales la identidad es un concepto vago, pues sus habitantes suelen tener mayores nociones de identificación con sus respectivas localidades que con la región. En ello tienen que ver tanto aspectos geográficos como históricos; así como los derivados del modelo de desarrollo del capitalismo en el ámbito nacional en el siglo xx. En ello, un elemento fundamental es la diferenciación social.

Palabras clave: sur de Jalisco, identidad, región, territorio, diferenciación social.

\begin{abstract}
Southern Jalisco is a region rich in representative cultural expressions of the identities of the different towns that integrate it. However, in this paper we argue that, in regional terms, identity is a vague concept as the inhabitants have greater notions of identification with their own localities than with the region. This has to do with geographical as well as historical aspects, together with the effects of the capitalist development model at a national level in the $20^{\text {th }}$ Century. Within this context, social differentiation plays a fundamental role.
\end{abstract}

Keywords: Southern Jalisco, identity, region, territory, social differentiation.

* Profesor investigador, Centro Universitario del Sur de la Universidad de Guadalajara. Correo-e: amacias40@hotmail.com y alejandro@cusur.udg.mx. 


\section{Introducción*}

El sur del estado de Jalisco, en el occidente de México (mapa 1), ${ }^{1}$ puede definirse, por razones tanto geográficas como históricas, como el área que comprende las tierras localizadas al suroeste del lago de Chapala y al noreste del volcán de Colima (De la Peña, 1992: 194). En este territorio se distinguen varias zonas geográficas: el valle de Zapotlán, el valle de Sayula, la Sierra de Tapalpa, la Sierra del Tigre, el macizo formado por el Nevado de Colima y el Volcán de Fuego, así como las cuencas intercomunicadas de Zapotiltic, Tuxpan, Tamazula, Pihuamo y Tecalitlán (Escobar y González de la Rocha, 1988: 33-34).

El sur de Jalisco es un territorio rico en muchos aspectos, empezando por la variedad de recursos naturales con que cuenta (tanto zonas serranas, como valles, lagunas y llanos), y continuando con su cultura, plagada de múltiples manifestaciones indígenas y mestizas, hombres prominentes (Juan Rulfo, José Clemente Orozco, Juan José Arreola, Consuelito Velásquez, entre otros) y gran pluralidad de tradiciones, principalmente religiosas.

Sin embargo, pese a que tal riqueza cultural de los pueblos sureños permite la existencia de claras manifestaciones identitarias en cada localidad, o en grupos sociales específicos, y a que dichos pueblos comparten una historia de cierta unidad que se ha mantenido con el paso de los años principalmente por razones administrativas y de explotación económica (Torres, 2005), y no obstante también las experiencias históricas comunes en su relación con el ambiente (en particular, las vivencias de catástrofes naturales de orden telúrico relacionadas con la cercanía al Volcán de Colima, y el hecho de estar en una zona sísmica), diversos elementos han hecho históricamente difícil consolidar una identidad regional.

* El presente documento forma parte del proyecto de investigación denominado "Empresas hortícola y desarrollo socioeconómico regional (el caso de Sayula, Jalisco)", que el autor dirige con apoyo económico del Centro Universitario del Sur de la Universidad de Guadalajara, el Programa para el Mejoramiento de Profesorado (PROMEP) de la Secretaría de Educación Pública, y el Centro de Investigaciones y Estudios Superiores en Antropología Social (CIESAS Occidente).

${ }^{1}$ Actualmente, el gobierno de Jalisco divide al sur del estado en dos regiones: sur, que comprende 16 municipios (Amacueca, Atemajac de Brizuela, Atoyac, Zapotlán El Grande, San Sebastián del Sur, Sayula, Tapalpa, Techaluta de Montenegro, Teocuitatlán de Corona, Toliman, Tonila, Tuxpan, San Gabriel, Zacoalco de Torres, Zapotiltic y Zapotitlán de Vadillo), y la región sureste, con 10 municipios (Concepción de Buenos Aires, Jilotlan de los Dolores, Santa María del Oro, Manzanilla de La Paz, Mazamitla, Pihuamo, Quitupan, Tamazula de Gordiano, Tecalitlán y Valle de Juárez). 


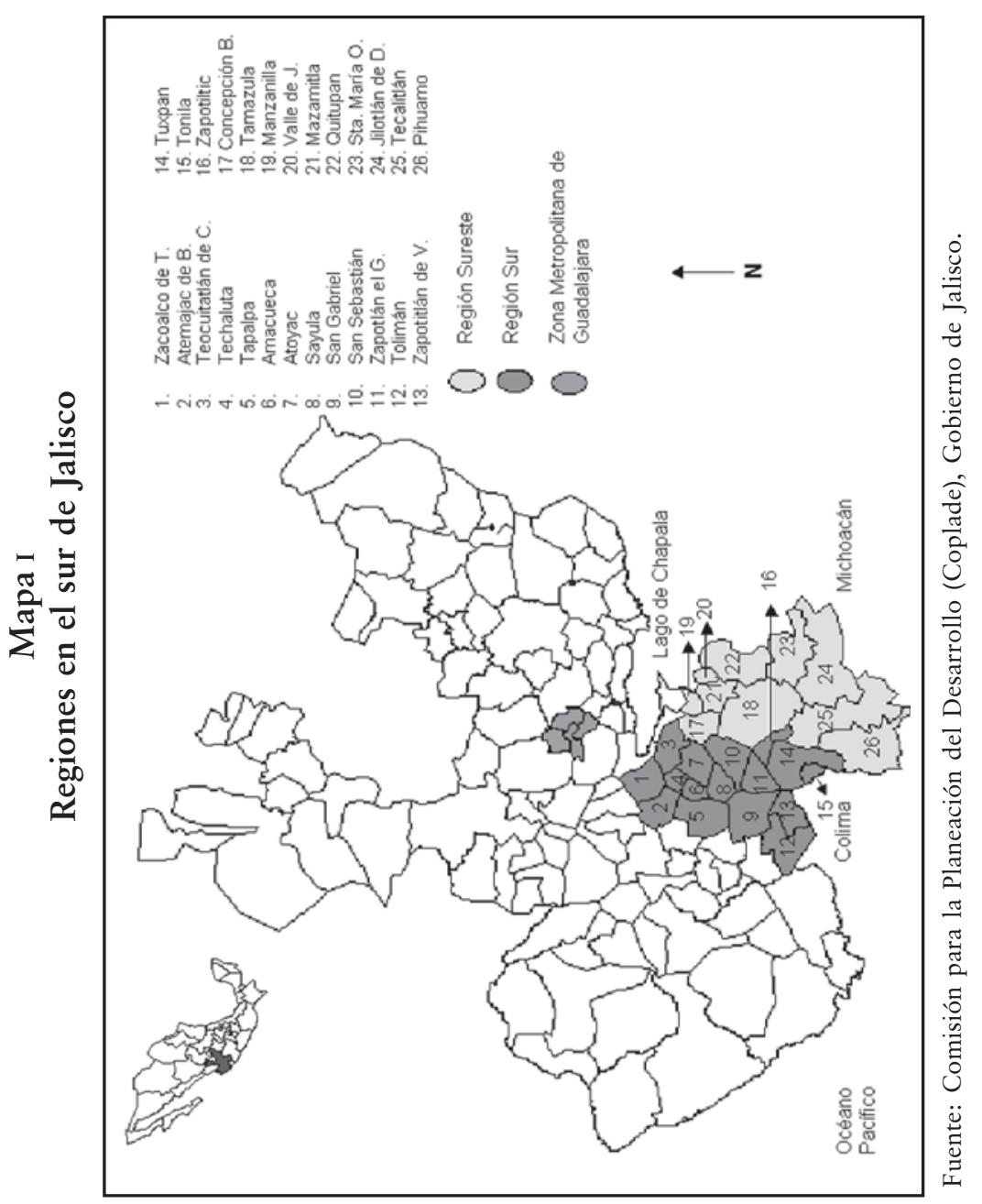


En el presente trabajo intento mostrar cómo estos factores, que van desde las características geofísicas hasta aspectos históricos, económicos, políticos y culturales, se han conjugado para que entre los habitantes del sur de Jalisco, a pesar de vivir en un territorio cuya historia es muy rica y de identificarse claramente con sus respectivos pueblos, no exista un sentimiento de pertenencia a una región común, como sucede en otras regiones incluso del propio estado de Jalisco (como la de Los Altos).

Ese dominio de las identidades locales sobre la identidad regional se ha manifestado en este territorio históricamente, pero con mayor intensidad a partir de la modernización económica, la irrupción del modelo de integración capitalista nacional y la ampliación del poder político por parte del Estado Federal en la primera mitad del siglo xx, elementos que provocaron la disminución de la fuerza de los grupos de poder locales y regionales, debilitando en consecuencia los factores que entonces permitían poder hablar de ese territorio como una región, no obstante las dificultades de comunicación existentes. ${ }^{2}$

En las dificultades para consolidar una identidad regional en el sur de Jalisco, un aspecto que, sin ser definitivo, ha tenido gran influencia, es la diferenciación social, de manera que en la medida en que ésta se incrementa y existe una mayor fragmentación entre los distintos grupos, los niveles de extrañamiento cultural también son mayores (cada grupo tiene intereses y cosmovisiones que, en la mayor parte de los casos, son altamente

\footnotetext{
${ }^{2}$ Cabe señalar que tal situación tampoco es ajena a la mayor parte de las zonas geográficas de Jalisco y a la propia entidad en su conjunto, la cual a pesar de mantener fuertes nexos identitarios hasta el siglo XIX, su "historia contemporánea resulta menos particular que en las épocas anteriores [ya que] lo acontecido en el Estado nacional durante el actual siglo [siglo $\mathrm{xx}$ ] responde con mayor uniformidad a lo acontecido en el resto de la Nación [...]" (Vaca et al., 1982: 12). De acuerdo con Guillermo de la Peña (1994: 217), se puede hablar de una cultura regional en el centro-occidente de México desde mediados del siglo XVIII y hasta el fin de la Guerra Cristera en la década de 1920. Incluso, durante la primera parte del siglo XIX, Jalisco lideró a los estados del occidente de México para la constitución de alianzas que enfrentaran la autonomía de las élites locales frente a las instancias burocráticas diseñadas por el Estado nacional para concentrar el poder (Olveda, 1994: 132). Durante años, Guadalajara, la capital de ese estado, era el único centro de la vida económica y política del occidente. Sin embargo, la cultura regional más o menos homogénea empezó a ser agredida por la Revolución, el reparto agrario, la expansión de las comunicaciones y los mercados y el surgimiento de un sistema político crecientemente centralizado durante la primera mitad del siglo xx (De la Peña, 1994: 218), lo cual afectó la identidad regional, además de que a partir de la segunda mitad del siglo xx, el área en la que se desbordaba Guadalajara cada vez fue más reducida ante la aparición de nuevos centros (Olveda, 1994: 134). De esta forma, el occidente de México ya no constituye una región homogénea, sino diversa y con marcados contrastes en su interior (Roberts, 1980), aun cuando hasta nuestros días la población de Jalisco siga siendo profundamente anticentralista (De la Peña, 1994: 220).
} 
contrastantes), disminuyendo con ello las posibilidades de consolidar patrones culturales compartidos que puedan afianzar procesos identitarios regionales.

Antes de iniciar con el análisis, conviene primero definir qué es lo que se entiende por identidad colectiva. Después examino los distintos elementos que hoy influyen en la conformación de las identidades colectivas en el sur de Jalisco, cuyas condiciones han ido cambiando conforme avanzó el siglo xx para llegar a un momento en el que la globalización y la reconfiguración del Estado nacional, más que favorecer al regionalismo, permitió el fortalecimiento de localismos, nunca desaparecidos pero sí opacados por la fuerza del nacionalismo posrevolucionario.

\section{Identidades colectivas o culturales}

Siguiendo a Gilberto Giménez (2000a: 27), desde un punto de vista relacional y situacionista, la identidad colectiva es "el conjunto de repertorios culturales interiorizados (representaciones, valores, símbolos, etc.) a través de los cuales los actores sociales (individuos o colectivos) demarcan simbólicamente sus fronteras y se distinguen de los demás actores en una situación determinada, todo ello en contextos históricamente específicos y socialmente estructurados".

Desde el punto de vista social, la identidad surge de una serie de actividades o acciones sociales que se entrelazan bajo proyectos políticos comunes (Lameiras, 1991: 62). Implica, además, un proceso de autorreconocimiento y diferenciación del sujeto respecto de los otros, de manera que mediante ella, éste se reconoce como parte de un grupo social, pero también como diferente a otros grupos sociales.

De acuerdo con Jorge Larrain (2004: 43-45), la identidad colectiva se conforma a partir de tres elementos: i) las categorías sociales compartidas; ii) los elementos materiales por medio de los cuales los seres humanos proyectan su ser y sus propias cualidades, permitiéndoles pertenecer o tener el sentimiento de pertenencia a una comunidad, y iii) la definición del sujeto desde el punto de vista de cómo lo ven los otros, tanto porque tales opiniones son internalizadas por el individuo, como porque por medio de los otros es como él adquiere un carácter distintivo y específico.

La identidad de un grupo social no sólo implica la manera como las comunidades se ven a sí mismas, sino también cómo son vistas desde el exterior, de manera que una identidad fuerte 
es aquélla cuyos elementos distintivos son señalados tanto en la mirada interna de sus miembros como en la externa (Giménez, 1987: 465; Vaca, 2003: 54). Estas identidades (también llamadas identidades culturales) se forjan con la participación de una serie de características culturales que comparten muchos individuos con antecedentes históricos y/o experiencias comunes.

Las identidades colectivas no son algo dado ni estático, sino que se trata de un rasgo dinámico, siempre construido y reconstruido de acuerdo con los retos que se le presentan a las sociedades en un permanente esfuerzo de aprendizaje y reaprendizaje de los individuos por medio de las acciones colectivas (Monsiváis, 2002: 297; Zárate, 2003: 50; Vázquez, 1997: 31). Así, una identidad puede crecer y desarrollarse, pero también declinar y morir, aunque siempre debe tenerse en cuenta la tesis de Fredrik Barth (1976), en el sentido de que las identidades se definen principalmente por sus diferencias, más que por el contenido cultural que en un momento determinado marca tales diferencias. Es decir, con el tiempo pueden transformarse las características culturales de un grupo sin que ello implique que perdió su identidad; más bien, lo que ha sucedido es un proceso de recomposición adaptativa (Giménez, 1994: 171-174).

El carácter dinámico de las identidades resulta más evidente en la actualidad que en el pasado. Larrain (2004: 60-63) señala tres razones por las que la actual globalización ha afectado a las identidades culturales formadas durante la modernidad:

a) Porque los medios masivos de comunicación han hecho que los individuos se relacionen (aunque sea virtualmente) con muchos otros sujetos y comunidades con los que no lo hacían antes. Con ello, la conexión entre lugar compartido y autoformación, aspecto característico en la conformación de las identidades anteriores a la globalización, se ha vuelto mucho menos nítida, y ahora los actores se apropian, a través de la televisión, la Internet u otros medios de comunicación, de algunos elementos culturales provenientes de lugares muy lejanos. No obstante, ello no deriva en una homogeneización de las culturas, pues los individuos reinterpretan lo que reciben del exterior de acuerdo con sus propias experiencias locales en gran parte definidas territorialmente.

b) Porque el ritmo de cambio en las relaciones se ha intensificado, siendo más difícil para el sujeto internalizar en su 
mente y comportamiento toda esa dinámica. Ello hace que surjan conciencias menos comprometidas con las grandes identidades universalmente reconocidas, como el Estado nacional, la clase, la etnicidad o la familia, y más comprometidas con lo efímero, lo contingente y el compromiso con grupos específicos. Como dice Ulrich Beck (2001: 234), "cualquier intento de crear un nuevo sentido de cohesión social tiene que partir del reconocimiento de que el individualismo, la diversidad y el escepticismo forman parte de la cultura occidental”.

c) No obstante, las identidades culturales, lejos de disolverse, se han reconstruido de acuerdo con las nuevas condiciones sociales, donde el actor, ante el maremagno de información y relaciones que tiene, se siente más en la necesidad de protegerse con su pertenencia a determinados grupos que representan su propia identidad.

Esas identidades se construyen local o regionalmente, pues es en el territorio, como espacio apropiado y valorizado por los grupos humanos que en él viven para asegurar su reproducción y la satisfacción de sus necesidades vitales -que pueden ser materiales o simbólicas- (Giménez, 1996: 2-3; 2001: 5-6), donde los actores sociales buscan la seguridad que la inestabilidad global no ofrece (Harvey, 1990: 306). De ahí que se observen cada vez más movimientos sociales que buscan la autonomía local, la organización basada en el lugar o el respeto por las identidades locales o regionales, todas ellas poniendo el énfasis en la potente conexión entre lugar e identidad social, de acuerdo con el argumento de que hoy se debe pensar globalmente, pero actuar localmente (Harvey, 1990: 302).

En resumen, si bien la época llamada por algunos posmoderna o modernidad tardía se caracteriza en gran medida por el rechazo a lo impuesto y la exaltación de lo efímero y de la mayor libertad individual, todo ello está mediado por estructuras socioculturales donde las identidades colectivas continúan manteniendo un papel fundamental, y en algunos casos hasta más importante ante la necesidad de las personas de buscar mecanismos de arraigo que les permitan sortear los incesantes cambios. Esas identidades, que todavía son el cimiento para la convivencia por su carácter histórico y cultural, no cambian tan rápido como quizá lo hagan las redes sociales, de manera que se van configurando y fortaleciendo por medio de dos fuentes distintas: 
Primera. Con la actuación diaria de los individuos; es decir, las conversaciones e intercambios cotidianos desarrollados por la gente en las relaciones que sostienen dentro de sus espacios locales. De acuerdo con Lourdes Celina Vázquez (1997: 43-44), cuando los procesos sociales no logran modificar las formas de ver el mundo y de expresarse en el trabajo diario y en la relación cotidiana, son procesos que no están enraizando y que no prometen una verdadera transformación.

La identidad construida por esta vía tiende, por lógica, a ser menos articulada y a tener un carácter más concreto y contradictorio, al tratarse de una conciencia práctica de lo que los actores saben sobre su propia realidad, pero que no expresan de una manera discursiva (Larrain, 2004: 55). Es decir, al ser formas de comportamiento natural y no racionalizadas por los sujetos, se dificulta enormemente su articulación en un discurso.

Ahora bien, aunque la identidad se desarrolla en la vida diaria, muchas de sus formas requieren la presencia de un grupo fuerte capaz de respaldar los elementos que la conforman. Sobre ello profundizaré más adelante.

Segunda. La identidad que se construye mediante los medios discursivos perfectamente articulados por un actor o grupo de actores que seleccionan, no siempre racionalmente, los símbolos, conversaciones, historias y valores que desean estén presentes en una identidad a imponer, aunque aparezcan como naturales o espontáneos. Estos discursos hablan de una identidad aparentemente uniforme que esconde detrás de sí la diversidad surgida en la vida diaria.

Sin embargo, resulta difícil pensar que la identidad, siendo un producto histórico, pueda simplemente modificarse con programas institucionales. Quizá a ello se deba el fracaso del esfuerzo del Estado mexicano por generar una identidad nacional en el periodo revolucionario y diluir en ella las identidades locales surgidas en la interacción de muchas generaciones. De hecho, cualquier identidad, por más planeada que esté desde los grupos de poder, es un espacio en constante lucha y negociación donde entran en juego los intereses y visiones de mundo de los distintos grupos dominantes de la comunidad, pero también las propias experiencias locales y/o populares.

Aquí es donde los intermediarios entre el aparato estatal y la comunidad, como pueden ser los caciques, las élites empresariales, las organizaciones comunitarias y otros muchos agentes que asumen este papel de puente, adquieren una gran importancia para la adecuada instrumentación de cualquier política que 
pretenda forjar o consolidar una identidad colectiva. Por eso es fundamental el papel que cumplen los grupos de poder, ya que aunque la identidad se desarrolla en la cotidianidad, ello no implica que sea simplemente un fenómeno espontáneo que surja sin más de las relaciones sociales, sino que, por el contrario, al regirse la sociedad mediante relaciones de poder, la identidad también es resultado de la manera como éste se configura y ejerce.

Ahora bien, la manera inmediata donde se pone en práctica la identidad en la organización territorial es la local, que corresponde a aquellas microsociedades municipales cuyos límites suelen no ser precisos ni coincidir necesariamente con demarcaciones político-administrativas (Giménez, 1996: 3), siendo lo que les da cohesión algún nicho ecológico del que se derivan actividades económicas, sociales, políticas y/o culturales con las que se identifican la mayor parte de sus habitantes. Cuando estos territorios locales, que son objeto de afección y apego, crecen más allá de las demarcaciones municipales, entonces puede conformarse una identidad regional.

\subsection{Configuración de las identidades regionales}

Para muchos investigadores como Bryan Roberts (1980: 10) o Guillermo de la Peña (1994: 216-217), la identidad de una región se forja mediante las imposiciones que realiza una clase o grupo social hegemónico con la fuerza suficiente para lograr integrar y articular los valores y estilos de vida de la comunidad y expandir su base material. Por ello, cuando los grupos sociales hegemónicos en una región son débiles en su intermediación ante fuerzas extraregionales, la identidad de esa región, si bien no desaparece (porque no existen personas ni pueblos sin identidad), sí suele fragmentarse y desarticularse cediendo el paso a la incorporación de otros elementos culturales venidos del exterior y que imponen sus propias pautas de desarrollo.

En este argumento hay una aparente contradicción con lo dicho anteriormente: si la identidad cultural se forja en la vida diaria, ¿por qué es necesario que haya un grupo social dominante para sostenerla? Tal contradicción se soluciona si se observa que lo que hace el grupo hegemónico es dar fortaleza y coherencia a una identidad que de por sí existe en la interacción social. A continuación explico este argumento.

En primer lugar, habría que preguntarse si realmente desaparecen los grupos sociales hegemónicos en una región cuando se dan cambios que cimbran su armonía interna, de manera 
que éstos vengan a ser sustituidos por fuerzas externas que a partir de ese momento marquen el devenir histórico regional. Una posición de tal naturaleza nos llevaría a ver al actor social como un ser indefenso ante la avalancha de fenómenos que le vienen del exterior (Long, 2001: 43), los cuales lo marginan del proceso de decisión y lo obligan simplemente a adaptarse de manera pasiva a los dictados de las grandes fuerzas nacionales o internacionales.

Pero esto no sucede así. Por el contrario, los actores sociales con mayor capacidad económica, política y cultural, no sólo para adaptarse sino también para fortalecerse en la nueva coyuntura, se convierten en parte de los grupos hegemónicos locales que funcionan como intermediarios en el proceso de interacción entre los agentes externos y la realidad interna.

Sin embargo, si las hegemonías locales no tienen la suficiente fuerza como grupo para servir como interlocutores frente a las fuerzas externas que incorporan nuevos elementos culturales en la localidad, la identidad sufrirá transformaciones de tal envergadura que puede perder la mayor parte de su cohesión, con consecuencias tales como provocar que muchos de sus habitantes se identifiquen cada vez menos como miembros de la comunidad al compartir menores cosas con los vecinos, y que la identidad híbrida resultante sea menos benéfica para un potencial desarrollo local endógeno.

Ante ello, la presencia de una fuerza dominante es básica para lograr que por lo menos los elementos que le dan mayor unidad al grupo, puedan conservar cierto nivel de coherencia y homogeneidad en la concepción de cada miembro, de manera que se mantenga una identidad. Claro que la presencia de un grupo dominante no garantiza por sí sola la viabilidad de determinados patrones identitarios, pues, como ya se dijo, la construcción de la identidad es un proceso dinámico. Pero lo que sí permiten esas hegemonías es su funcionalidad al servir como puente en la integración de los factores socioculturales externos con los elementos locales, sin que ello se dé con mayores sobresaltos. ${ }^{3}$ Lo anterior debe considerarse sin dejar de reconocer que tanto las fuerzas internas como las externas se componen de individuos con diferentes intereses personales y de grupo, de manera que la mediación no es un proceso monolíti-

\footnotetext{
${ }^{3}$ De hecho, estos grupos, que en muchas ocasiones forman la burguesía regional, fueron en varias regiones de México elementos de mediación fundamentales para la actividad del gobierno federal en el ámbito local.
} 
co sino un mosaico multivariado, compuesto por un gran tejido de interlocuciones.

Ahora bien, entre más pequeño sea el grupo, los factores culturales que comparten sus miembros serán mucho más nítidos e incorporados en sus respectivos comportamientos, pues los actores sociales estarán constantemente intercambiando experiencias respecto a la traducción y reconfiguración de los fenómenos. Sin embargo, en la medida en que el grupo crece, las características culturales (además de las físicas) que le dan unidad disminuyen y se vuelven más difusas, pues los actores sociales que forman comunidades imaginadas, ${ }^{4}$ tienen menor oportunidad de reforzar el intercambio de experiencias sobre la resignificación de los elementos compartidos y, con ello, tales elementos serán traducidos de manera distinta al interior de los diferentes subgrupos que se constituyen.

Por eso, si es muy difícil que la identidad local se pierda con la irrupción de fuerzas externas, sí es factible que la identidad regional se diluya debido a la propia separación geográfica y de intereses entre las distintas localidades. Y si esto sucede en el ámbito regional, obviamente es mayor el riesgo en el plano nacional, al ser sus fronteras físicas y socioculturales mucho más amplias que las de una región, y evidentemente más diversas las experiencias históricas de sus miembros.

Sin embargo, un elemento fundamental con que cuenta la nación y no la región para evitar esa pérdida de identidad, es la presencia de una fuerza hegemónica importante como es el Estado nacional y todas sus instituciones, e incluso las élites económicas empresariales, las cuales permiten que la identidad nacional se reconstruya pero no se pierda.

Pero en el caso de las regiones mexicanas, no existen gobiernos regionales que cumplan esa función, por lo que los únicos que pueden salvaguardar la identidad regional son los grupos hegemónicos con la fuerza suficiente para que la misma, aunque se transforme en el intercambio con el exterior, no se vea resquebrajada.

Ahora bien, uno de los problemas importantes que se vivieron en México durante el siglo XIx fue la desarticulación con la que los poderes locales y regionales superaban la capacidad del

\footnotetext{
${ }^{4}$ Benedict Anderson (1993: 23-24) señala que la mayor parte de los grupos, y sobre todo en la medida en que éstos crecen en número y en dimensión espacial, deben ser vistos como comunidades imaginadas construidas culturalmente, pues la mayoría de sus miembros no se conocerán nunca y algunos ni siquiera sabrán de la existencia de otros, pero, a pesar de ello, hay una serie de factores que permiten que en la mente de cada uno exista la imagen de comunión con los demás miembros del grupo.
} 
Estado nacional para lograr la prevalecencia de su poder en todo el país. La nación como tal prácticamente era nula; los grupos se identificaban mucho más con su localidad que con la nación, e incluso para algunos, tal palabra era totalmente ajena. Sólo las élites políticas ilustradas tenían una conciencia nacional (Zárate, 1997: 260). Éste es precisamente el origen de los caudillismos regionales, así como de los muchos problemas separatistas que el país vivió en esos años.

Sin embargo, después de la Revolución Mexicana el esfuerzo del Estado federal se orientó a consolidar la identidad nacional mediante la creación de una conciencia que fortaleciera la homogeneidad étnica y cultural. Para ello ejerció una serie de estrategias que le permitieran fortalecer su poder, centralizándolo de una manera más eficaz y comprehensiva (De la Peña, 1977: 1). Dentro de esas estrategias socioeconómicas, políticas y culturales estuvo la de desarticular las regiones, sobre todo donde las mismas eran un obstáculo para los planes nacionales, para lo cual se privilegiaron a aquellos grupos económicos que tuvieran mayores nexos en los ámbitos nacional e internacional por encima de las élites regionales: "No podían permitirse más las estrategias localistas que organizaban los recursos regionales de acuerdo a los intereses internos de la región. Los beneficiarios debían ser ahora los representantes de la articulación de la economía nacional con el mercado mundial" (De la Peña, 1977: 22).

Esas decisiones ocasionaron una importante desarticulación de los sistemas productivos regionales, sobre todo en aquellos lugares cuyas élites no habían sido capaces de integrarse eficientemente a las redes económicas nacionales, como fue el caso de muchas de las regiones rurales. Ello es precisamente lo que sucedió en el sur de Jalisco (como en la mayor parte de ese estado), pues durante la primera mitad del siglo xx, la mayor parte de los grupos hegemónicos fueron profundamente debilitados, y aunque no se puede decir que hayan desaparecido las élites económicas y políticas locales, éstas sí fueron cambiadas en su mayoría, y las que surgieron lo hicieron no sobre la base del sostenimiento de una fuerza regional capaz de mantener su identidad, sino al amparo de las oportunidades que generó el modelo de inserción mexicana al capitalismo, el cual fue dominado por fuerzas externas a la región. 


\section{Las identidades en el sur de Jalisco}

En el caso del sur de Jalisco, para entender cómo funciona una potencial identidad regional es bueno partir de las principales manifestaciones identitarias en la región de Los Altos (en el mismo estado), con objeto de poder contrastarlas con la región de estudio.

A pesar de que los habitantes de distintos pueblos de Los Altos suelen tener conflictos, cuando se trata de defender la región ante cualquier agente externo, todos se identifican con una causa común. Por eso el habitante de Los Altos no duda en reconocerse como alteño antes que como jalisciense o mexicano (Vaca, 2003: 55). Incluso, se identifica primero como alteño y después como habitante del pueblo en el que vive.

A grandes rasgos, la fuerte identidad colectiva que existe en Los Altos tiene las siguientes causas:

a) Son pueblos donde no había una gran cultura indígena, de manera que la colonización propició que la cultura hispánica pudiera imponerse como hegemónica sin haber un gran mestizaje cultural (Zárate, 1997: 41).

b) Como resultado de lo anterior, y por sus características agroecológicas, ${ }^{5}$ esa región fue formada principalmente por rancheros, entendidos éstos como lo hace Luis González (mencionado por Shadow, 1994: 167); es decir, como "aquellos pobladores libres de las tierras flacas del Occidente de México, cómodos al residir junto a sus propiedades, portadores de una cultura e identidad más española y criolla que indígena y que viven en una economía agroganadera basada en la explotación privada de la tierra".

c) Al constituirse la región como una sociedad mayoritariamente criolla y ranchera y con patrones étnicos y culturales poco diferenciados, existió una escasa división del trabajo y diferenciación social que los ha hecho construir una identidad muy bien perfilada (Vázquez, 1997: 32).

d) Pero, además, tal identidad se ve fortalecida por tratarse de una región geográficamente poco accidentada,

\footnotetext{
${ }^{5}$ Para Robert Shadow (1994: 176) tales características son: un régimen climatológico y geográfico no apto para la agricultura intensiva, cierta distancia de los mercados urbanos, un patrón discontinuo en la distribución de las tierras cultivables, población indígena escasa, baja densidad de población como resultado de que son tierras poco atractivas para la agricultura intensiva, y una estructura étnica favorable para la implantación de la cultura española.
} 
donde los habitantes de los distintos pueblos mantienen constante comunicación entre sí.

e) Lo anterior hace que en Los Altos "exista una identidad que unifica a todos sus habitantes y los hace portadores orgullosos de su origen regional, a pesar de la intromisión de patrones culturales ajenos" (Vázquez, 1997: 18).

¿Qué sucede en el sur de Jalisco?, ¿̇uáles son las diferencias que permiten argumentar que mientras en Los Altos se puede hablar de una fuerte identidad regional, en el sur del estado no sucede tal cosa? Para responder a estas preguntas, confrontemos cada uno de los aspectos anteriores. Para ello acudiré a información empírica reportada por otros autores en distintos documentos, así como a información del trabajo de campo que realicé entre junio de 2003 y julio de 2004 en el municipio de Sayula, dentro del proyecto de investigación denominado "Empresas hortícolas y desarrollo socioeconómico regional (el caso de Sayula, Jalisco)". En ese trabajo apliqué diversas entrevistas semiestructuradas a distintos actores de la sociedad sayulense, en particular a personas relacionadas directa o indirectamente con la producción de hortalizas, algunos de cuyos comentarios son pertinentes para el tema que trato en este documento.

\subsection{Mestizaje cultural}

A diferencia de Los Altos, la colonización en el sur se dio ante importantes grupos indígenas allí asentados. ${ }^{6}$ Aunque la conquista en general fue pacífica -como lo señalan Federico Munguía ([1976], 1998: 31), Juan José González (2001: 180) y Juan Vizcaíno (1991: 5), para el caso de los pueblos del valle de Sayula y Zapotlán, o Jesús Torres y Salvador Yánez (2003: 55) para la

${ }^{6}$ El sur de Jalisco, muchos siglos antes de nuestra era, se presume que fue habitado por tribus como los otomíes, los olmecas, pinos, cocas y, principalmente, los nahoas, que conjuntamente con los otros pueblos allí asentados, dieron origen a razas mestizas importantes en el occidente de México, como los tepehuanes (González, 2001: 177). Los nahoas desaparecieron diez siglos antes de la llegada de los españoles (Munguía, 1998: 17-18), pero muchas de sus tradiciones fueron retomadas por civilizaciones que después se asentaron allí, como toltecas, zapotecas, totonacas y, sobre todo, chichimecas, chimalhuacanos y aztecas, que contribuyeron a formar las razas que los españoles encontraron (González, 2001: 178). Posteriormente, el sur de Jalisco fue ocupado también por reinos como el purépecha y el de Coliman, que peleaban por las salinas de las lagunas de Sayula y Zacoalco. Por último, cabe señalar que las diversas tribus que estuvieron en la zona por lo general eran trashumantes que estaban sólo por unos años, mezclándose algunos de ellos con los residentes (Munguía, 1998: 19). 
Sierra del Tigre-, el proceso de colonización en ocasiones trajo enfrentamientos entre los descendientes de los españoles y los indígenas. Esos enfrentamientos eran principalmente por la propiedad de las tierras, pero también por choques culturales, mismos que no se resolvieron hasta muy entrado el siglo xx, y en algunos casos todavía perduran.

Algunos pasajes del libro La feria, escrito en 1963 por Juan José Arreola, originario de Zapotlán El Grande y uno de los más ilustres literatos de la región, dejan ver esa relación conflictiva:

A mí que no me vengan con cosas, los indios han sido siempre enemigos del progreso en este pueblo. ¿Sabe usted lo que escribieron al rey de España en 1633, cuando se dispuso aquí la construcción de un ingenio azucarero? 'Somos pobres indios menores. Por amor de Dios hacemos suplicación del decreto; no queremos que haya cañaverales en nuestra tierra...' Y nos quedamos reducidos al puro cultivo del maíz por culpa de estos llorones" (Arreola, 1992: 142).

En el fondo de estas expresiones subsiste una elevada discriminación étnica, donde los españoles y sus descendientes criollos y mestizos se autodefinían como gente de razón en contraposición a los naturales; es decir, los indios originarios de esas tierras.

En cuanto a los problemas de tierras, Guillermo de la Peña (1979: 57; 1991: 17) señala cómo desde finales del siglo XVIII y durante el XIX, los indígenas de Zapotlán el Grande (como los de muchas partes del sur de Jalisco y del país) fueron prácticamente despojados de sus tierras por parte de los grupos de la burguesía local, que al mismo tiempo ocupaban los principales cargos en el gobierno municipal. Así, al amparo de las leyes de desamortización liberal que disolvieron las corporaciones y convirtieron a los indígenas en propietarios, en combinación con una ley estatal de 1894 que facultaba a las autoridades municipales a realizar el reparto de los antiguos ejidos, y la práctica de los comerciantes adinerados de la época de prestar dinero a los indígenas, reteniéndoles en prenda los títulos de tierra, los que se adjudicaban si la deuda no era saldada a tiempo, prácticamente se arrebató a los indígenas su tierra, a tal grado que ni siquiera pudieron conservar la integridad de sus barrios y fueron empujados hacia la periferia del pueblo (De la Peña, 1991: 17). De esta forma, si en 1809 la tierra de Zapotlán en poder de los indígenas ascendía a 21 mil hectáreas, para 1857 sólo era de 3,600, y para 1900 apenas si llegaba a 50 o 60 hectáreas (Safa, 1988: 2). 
A pesar de lo anterior, la lucha por recuperar la tierra no se perdió entre los descendientes de los indígenas durante el siglo Xx. Así, una vez más en el libro La feria, los terratenientes reconocen tal situación:

Que no le quepa a usted la menor duda, todo lo suyo y lo mío, lo que todos los agricultores de Zapotlán hemos comprado con tantos sacrificios, hasta el último terrón, les pertenece a esta bola de cabrones... Todo el valle de Zapotlán es de ellos, según les están metiendo en la cabeza los historiadores y tinterillos que azuzan contra nosotros. Cincuenta y cuatro mil hectáreas de sembradura, sin contar las tierras de la Comunidad Agraria porque eso sí, ellos no van a meterse con el Gobierno (Arreola, 1992: 134-135).

Incluso, todavía en 1978 hubo una invasión de tierras en el lugar conocido como Piedra Ancha, donde los invasores apelaban a los derechos de la comunidad indígena (De la Peña, 1991: 13).

Otro caso del choque étnico en esa región, que después se recrudeció por cuestiones de diferenciación socioeconómica, sucedió en el municipio de Sayula, población que en la época prehispánica fue cabecera de un importante pueblo, Tlatoanzago Zaulteco (Munguía, 1987). Sin embargo, después de la conquista, y debido a sus excelentes condiciones ecológicas, esa localidad se convirtió en el principal asentamiento de los españoles en todo el sur de Jalisco, conformándose la provincia de Ávalos.

Resultado de ambos fenómenos, Sayula presenta un mosaico de culturas hispánicas e indígenas que no terminan por asimilarse. Mientras que la cabecera municipal se identifica con su pasado colonial, 7 subsisten también, sobre todo en la zona de Usmajac (pueblo semirural ubicado al este de la cabecera municipal), importantes manifestaciones culturales indígenas, pues las tierras al norte de ese pueblo -donde después se construyó la hacienda de Amatitlán- eran propiedad de nativos. ${ }^{8}$

Este contraste entre culturas se manifiesta en las diferencias entre la cabecera municipal de Sayula y Usmajac: mientras la

${ }^{7}$ Como se muestra en el siguiente fragmento, escrito en los años treinta por la poetisa Helena de la Mora Villalvazo (mencionado por Munguía, 1998: 307)

Pared de cal y canto, pilares de cantera,

Casonas con su añejo sabor a colonial...

Jardín cuyo perfume envidia la pradera,

En donde un sol de fuego tortura a la palmera

Que sueña con la dulce frescura del portal.

${ }^{8}$ Prueba de ello es que en 1879 la población de Sayula era de 11,955 habitantes, 5,205 de los cuales eran indígenas (Munguía, 1998: 191). 
primera tiene un mayor ingreso económico, es una localidad más diversificada -sobre todo por la presencia del comercio-, y vive allí la gente con mayores recursos económicos, Usmajac es una población semirural que continúa viviendo casi exclusivamente de la agricultura. Tal situación heterogénea entre ambas poblaciones -que tiene su origen no sólo en su pasado étnico, sino también en la dinámica económica de ello derivada- provocó que paulatinamente fueran creciendo los enfrentamientos entre sayulenses y usmajaquenses, donde los segundos se sienten tradicionalmente relegados de las mejores oportunidades económicas, pues, dicen, la cabecera municipal acapara la mayor parte de los recursos que el municipio genera por estar allí la sede del poder municipal.

Lo anterior se agrava por el hecho de que una de las principales actividades económicas del municipio todavía es la agricultura, siendo que las tierras más aptas para los cultivos comerciales hoy más importantes -como el brócoli o las semillas mejoradasse concentran al sureste, en el lado de Usmajac. Ante ello, los habitantes de esa población dicen que el corazón del valle se localiza en torno a Usmajac (Gómez, 2004), pero que todo lo que se resuelve en materia de agricultura es en beneficio de los productores hortícolas que viven en Sayula. Existe por tanto, un sentimiento de trato injusto entre los habitantes de Usmajac, lo cual hace que no se sientan parte del municipio de Sayula. Esa falta de identificación se comprueba en el siguiente comentario hecho por un usmajaquense: "Las empresas vienen de Sayula..., pero aquí en la región...”, como si la región se constriñera exclusivamente a Usmajac.

En cuanto al ámbito de las representaciones culturales, si bien en algunos casos los choques étnicos se fueron transformando en la interrelación y complementariedad de ambas culturas, en otros no han terminado de consolidarse en una cultura más o menos homogénea. Por eso, todavía hoy se mantienen importantes manifestaciones culturales de origen indígena, gran parte de las cuales se concentran en el valle de Sayula-Zapotlán: Zacoalco, Cuyuacapán, San Andrés Ixtlán y Tuxpan, así como en la parte posterior de la Sierra de Tapalpa: Atacco, Jiquilpan, Alista y los pueblos colindantes con el Cerro de El Petacal (Vázquez, 1997: 76). Por ejemplo, en el caso de Sayula, su diversidad étnica, cuyos resquicios todavía siguen presentes, se manifiesta en las celebraciones: mientras el carnaval (de renombre en Jalisco) es de origen criollo, la Fiesta de los Naturales sigue siendo una celebración cuasi indígena que se mantiene principalmente 
en los barrios pobres de Sayula, al identificarse estos como los herederos de las tribus otomíes, en contraste con las clases medias y altas (denominados "curros"), que destacan por su pasado español (Vázquez, 1997: 150).

Incluso en aquellas manifestaciones que ya se encuentran más mestizadas, existen resquicios étnicos que hoy se reivindican en términos de clase. Tomemos por ejemplo el caso de la fiesta de San José en Zapotlán El Grande, misma que refiere al mito sobre la fundación de la sociedad zapotlense (De la Peña, 1991: 14) y, por lo tanto, es un rito fundamental en la identidad de sus habitantes.

El origen de esa fiesta es un juramento que en 1749 hicieran los habitantes a una imagen de San José -imagen que, según la leyenda, dejó un viajero desconocido en una caja junto con otra de la Virgen del Rosario en la pequeña población indígena La Cofradía del Rosario, hecho que el párroco de Zapotlán interpretó como una señal divina- para que los librara de las catástrofes de los temblores, luego de que hubo uno muy fuerte el 22 de octubre de ese año. Por ello, los pobladores se comprometieron a celebrar cada 22 y 23 de octubre una misa, seguida de una gran procesión.

En las fiestas josefinas se refleja la formación colonial de Zapotlán como una comunidad jerárquica, desigual y participativa (De la Peña, 1991: 16), pues hasta el siglo XIX, y en algunas cosas ya entrado el siglo $\mathrm{xx}$, mientras los indígenas hacían sus danzas como sonajeros ${ }^{9}$ y se encargaban de actividades como la preparación de los fuegos artificiales ${ }^{10}$ o la elaboración de los endosos, ${ }^{11}$ su participación en los actos ceremoniales era de subordinación e incluso como comparsas, ya que los criollos se apropiaron de la conducción de las fiestas

${ }^{9}$ Aunque cabe señalar que la tradición de los sonajeros no es propiamente de ese municipio, pues, a decir de Guillermo Jiménez, 1988: 65), el sacerdote Atenógenes Silva, cuando fue cura de Zapotlán (1880-1883), "suprimió todas las fiestas y jolgorios de los indios [...], evitando que se celebraran sus matrimonios como los paganos, en fin, arrancó a la pobre raza idólatra y supersticiosa casi todas sus milenarias costumbres". Ante tal circunstancia, y de acuerdo con la hipótesis de Fernando Castolo (2004: 14), debido a la necesidad de los grupos indígenas de estimular la festividad en torno a la figura de San José, fue que fomentaron la importación de algunas tradiciones de pueblos circunvecinos, como, en este caso, del pueblo de Tuxpan. Esto demuestra el proceso de hibridación cultural que se da entre los pueblos vecinos aun sin la clara evidencia de una identidad regional.

${ }^{10}$ Por cierto, de Zapotlán sus propios moradores dicen que es un pueblo "cohetero", dado que durante el año son constantes las celebraciones religiosas que se adornan con el sonar de los cohetes.

${ }^{11}$ Tapices de flores multicolores que se colocan en las puertas de los templos. 
por medio del mayordomo, que era elegido por rifa cada año, y con diversas estrategias se impedía la participación de los indígenas. Una de ellas era contravenir lo estipulado en los juramentos, en donde se destacaba que las fiestas debían realizarse con la cooperación de todos los vecinos bajo la conducción del mayordomo, ya que en la práctica éste asumía la totalidad de los gastos. De esta forma se lograban dos metas: una, aprovechar la organización para que el mayordomo hiciera un gran derroche de dinero y con ello demostrara su superioridad económica, y otra, hacer prácticamente imposible para las clases populares y comunidades indígenas, adquirir alguno de los números de la rifa (que, por cierto, también eran muy caros). ${ }^{12}$

Por otro lado, una pregunta que se desprende de la devoción zapotlense a San José, y que otra vez remite a ese proceso étnico discriminatorio, es la siguiente: si ese pueblo fue llamado originalmente por los españoles como Santa María de la Asunción de Zapotlán, y si se encontraron las imágenes de San José y de la Virgen del Rosario, ¿̇por qué se decidió elegir como patrono a San José y no a la Virgen? Según Juan Vizcaíno (1991: 8), la razón fue que a finales de 1747 se jugaron unas elecciones en las que San José resultó electo para ser venerado públicamente. Sin embargo, otra explicación puede ser que San José había sido elegido por los españoles como patrono de las nuevas tierras conquistadas, de manera que se asociaba con el sector español en el México colonial. ${ }^{13}$

Ahora bien, en rituales que como el de San José fue necesaria la participación conjunta de la "gente de razón" y de "los naturales"; estos últimos aparecen en estado de subordinación, incluso hoy cuando la lucha étnica ha sido transformada en una lucha de clases por los descendientes mestizos. Así, por ejemplo, mientras las clases altas participan en la procesión religiosa como charros montados a caballo y en carros alegóricos, y

12 Tal situación duró hasta 1955, pues para las fiestas de 1956, según Castolo (2004: 21-23), el indígena Cirilo Ambrosio se atrevió a desafiar esas normas, comprando un número que resultó triunfador ante la indignación de los ricos del pueblo, "que exigieron al párroco no se permitiera tal atrocidad". Sin embargo, fue hasta 1972 cuando se determinó que no debían existir distinciones entre todas las personas que desearan participar en la rifa, retomándose los compromisos del juramento a San José, sobre la participación monetaria de todos los feligreses.

${ }^{13}$ De hecho, según Castolo (2004: 8), la historia que se cuenta sobre la aparición milagrosa de las imágenes no deja de ser una leyenda, pues en la realidad, las imágenes fueron mandadas hacer ex profeso a Guatemala por las autoridades eclesiásticas de Zapotlán, y si las esculturas se encontraron en Cofradía del Rosario es porque, según este autor, esa población funcionaba entonces como una especie de centro aduanal para Zapotlán. 
que por lo regular son gente de piel blanca, los danzantes de origen indígena participan a pie. Esto permite una representación que simboliza las diferencias étnicas y de clase, pues los descendientes de los criollos adinerados toman parte en la procesión viendo desde lo alto a los descendientes indígenas pertenecientes a las clases populares.

Ahora bien, a pesar de lo anterior, los grupos subordinados también se rebelan a las normas, de manera que en el propio festejo ritual reivindican un papel protagónico. Así, en la fiesta a San José, los indios y sus descendientes se han convertido en los únicos facultados para custodiar y cargar la imagen de San José, tanto en la fiesta como fuera de ella (lo cual hacen en andas; es decir, grupos de personas que cargan a cuestas el trono con San José y la Virgen del Rosario). Ello pudo lograrse como resultado de los hechos ocurridos en las fiestas de 1890, cuando llovía tanto que parecía imposible realizar la tradicional procesión y los actos al aire libre. En esa ocasión, fueron los indígenas quienes la mañana del 21 de octubre pidieron permiso a las autoridades civiles y eclesiásticas para sacar a San José en procesión a fin de calmar la lluvia. Así lo hicieron, y como la lluvia cesó, se interpretó como signo de benevolencia divina (Vizcaíno, 1990: 16), lo que les dio el poder de tener una relación directa con el santo.

Igualmente, las fiestas de origen indígena se han convertido en prácticas culturales diferenciadas que se utilizan para reivindicar ciertas clases y grupos sociales que mantienen una postura diferente a la de la explotación económica capitalista de las tradiciones culturales. Es el caso de la fiesta de San Francisco, llevada a cabo por la Cofradía de los Moros en colonias periféricas de Zacoalco de Torres (Zanotelli, 2005), la cual a pesar de ser realizada por mestizos, éstos tienen antecedentes indígenas que los identifica con una celebración hasta ahora no entendida e incluso despreciada por el resto de la población asentada en el centro del pueblo.

En resumen, la interrelación y asimilación incompleta entre la cultura española y la indígena, generó en el sur de Jalisco pueblos con una gran división del trabajo y jerarquización social, así como regiones muy diferenciadas y con objetivos heterogéneos, lo que poco abonó para la consolidación de una identidad regional, no obstante que determinadas fiestas se han convertido en parte fundamental de las identidades de pueblos específicos. 


\subsection{Características geográficas}

Las condiciones geográficas evidentemente influyen en la conformación de una identidad regional, sobre todo en las épocas pasadas, cuando los medios de comunicación no estaban tan avanzados. Si una región tiene una geografía poco accidentada, la comunicación entre los pueblos será más intensa y fluida y se generarán mayores elementos de identificación entre sus habitantes. Pero cuando sucede lo contrario y esto dificulta el tránsito entre los pueblos, evidentemente habrá menos intercambio de información y experiencias entre ellos y se tendrán pocos elementos que los identifiquen como parte de un mismo proceso histórico.

Lo primero ayudó a Los Altos a afianzar su identidad, en tanto que lo segundo ha influido bastante para que la identidad regional en el sur no esté tan consolidada, puesto que ese territorio presenta una geografía sumamente accidentada puesto que la atraviesa la Sierra del Tigre, la Sierra de Tapalpa y la Sierra del Volcán de Colima. Producto de ello, la región presenta una gran variedad geográfica, con fértiles valles -como el de Sayula y Zacoalco-, otros con menor fertilidad y condiciones naturales muy particulares -como el de Zapotlán-, zonas montañosas en donde se ubican poblados -como Atemajac de Brizuela, Tapalpa y Mazamitla-, áreas poco productivas para la explotación agrícola intensiva -como las que se localizan en el municipio de Valle de Guadalupe y los pueblos de la Sierra del Tigre-, tierras secas y de clima caliente -como el Llano Grande, ubicado al occidente de la región-, así como otras zonas con dificultades para establecer líneas de comunicación -como la que Esteban Barragán (1991: 57) llama "los declives de las sierras jalmichanas"; es decir, la zona de los municipios de Jilotlán de los Dolores y Santa María del Oro, que se extiende al extremo sureste de Jalisco y que colinda con el sur de Michoacán, misma que se caracteriza por su dispersión poblacional y aislamiento del medio urbano, así como por el difícil acceso.

Tal heterogeneidad del territorio, derivada de su accidentada geografía, desde un principio dificultó las comunicaciones entre los pueblos, lo que disminuyó los elementos de identificación e incluso aumentó los de confrontación, como se observa en el siguiente párrafo de La feria, de Arreola (1992: 20): 
pueblo y otro está la cuesta, un enredijo de curvas, paredones y desfiladeros que son la suma de nuestras dificultades [...] Y por el otro lado Tamazula, con el mal paso del Río de Cobianes que cada año nos separa con las crecidas, como un largo pleito. Así son las cosas, todo lo malo nos llega de fuera, por un lado Tamazula y por el otro Sayula. ${ }^{14}$

La situación señalada en el comentario anterior ya no es tan problemática como lo describe Arreola, pues las vías de comunicación que se han ido creando con el paso de los años, y que culminaron con la autopista Guadalajara-Manzanillo, abatieron de manera muy importante los tiempos de recorrido. Pero a fines del siglo XIX, poco antes de la llegada del ferrocarril, la situación era muy diferente, ya que, por ejemplo, el viaje en diligencia de Sayula a Guadalajara (cuya distancia es de sólo 100 kilómetros), se hacía en día y medio (Munguía, 1998: 199), en tanto que en la década de 1930, la distancia en ferrocarril entre ambas poblaciones se recorría en cinco horas, y con la carretera libre, se disminuyó a tres o cuatro horas el tiempo de trayecto (Murguía, 1998: 310).

La ampliación en las vías de comunicación durante el pasado siglo puede considerarse como un avance para la integración regional y acrecentar la identidad. Sin embargo, más que favorecer dicha integración, lo que provocó fue una mayor desarticulación regional, debido a que si bien es cierto que las vías de comunicación conectaron a las más importantes localidades con otras ciudades de Jalisco y el resto del país, facilitando los intercambios, al mismo tiempo promovieron una mayor injerencia del proyecto nacional y de los intereses extraregionales que debilitaron a la élite que respaldaba la identidad regional existente.

Además, la forma en que fueron tendidas las líneas de ferrocarril y después las carreteras, originó el aislamiento de muchos pueblos serranos, lo cual duró hasta prácticamente el tercer cuarto del siglo Xx, como puede verse en el siguiente comentario de una habitante de la Sierra del Tigre: "En el 69 me trasladé a la sierra, a Unión de Guadalupe, al rancho [...] Yo me casé en el 69 y me embaracé hasta tres años después, en el 72. Entonces todos mis embarazos los pasé en el rancho y en tiempos de aguas, el que iba a Guadalajara a ver al ginecólogo era mi esposo porque

${ }^{14}$ Actualmente Zapotlán El Grande es la principal ciudad en la región, en tanto que Sayula fue la más importante hasta principios del siglo xx. Tamazula es la otra ciudad que tomó relevancia regional sobre todo a raíz de que allí se ubicó el ingenio Tamazula en la primera mitad del siglo xx. 
no había manera de transitar en vehículo, solamente a lomo de bestia". 15

En la actualidad todavía existen poblaciones relativamente aisladas del resto de la región, como Chiquilistán, Ferrería de Tula, Juanacatlán y Atemajac de Brizuela, en la sierra de Tapalpa; Zapotitlán de Vadillo, La Barranca Honda, Alista y los pueblos circundantes al Cerro del Petacal, en el suroccidente, y Santa María del Oro, Jilotlán y Quitupan, en el sureste. ${ }^{16}$ La mayoría de esos pueblos son los que mantienen los más bajos niveles de desarrollo económico en Jalisco (Macías, 2001).

En resumen: a diferencia de Los Altos, la accidentada geografía del sur de Jalisco dificultó enormemente las posibilidades de comunicación y configuración de una identidad regional. Por ello, hasta hace muy poco las personas de distintos pueblos veían como "fuereños", a aquéllos distintos a su cultura y costumbres, a quienes provenían de otros municipios de la región. Nuevamente, esa situación se observa en el siguiente fragmento de La feria:

Y nosotros salimos ganando porque la feria de Zapotlán se hizo tan famosa por todo este rumbo. Como que no hay otra igual. Nadie se arrepiente cuando viene a pasar esos días con nosotros. De todas partes, de cerquitas y de lejos, de San Sebastián, de Zapotiltic, de Pihuamo y desde Jilotlán de los Dolores. Da gusto ver al pueblo lleno de fuereños, que traen sombreros y cobijas de otro modo, guaraches que no se ven por aquí. Nomás al verles la traza se saben si vienen de la sierra o de la costa (Arreola [1963], 1992: 19).

Pero si las condiciones físicas e históricas dificultaron la consolidación de una identidad regional en el sur de Jalisco, la historia reciente ha influido bastante para que se acreciente tal problemática.

\subsection{La desarticulación del sur de Jalisco}

A pesar de las dificultades para conformar una identidad regional, señaladas en los dos puntos anteriores, hasta mediados del siglo XIX existían elementos que permitían hablar del sur de Jalis-

${ }^{15}$ Entrevista a la señora Teresa Chávez Widemann, el 9 de julio de 2003, en Zapotlán El Grande, Jalisco.

${ }^{16}$ Respecto a los municipios de Santa María del Oro y Jilotlán, Esteban Barragán (1991: 60) los llama el rostro insólito del sur de Jalisco, describiéndolos de la siguiente forma: "municipios débilmente poblados, de relieve tupido y escarpado, con poca superficie laborable, lluvias escasas y dificultad para retener el agua, con raras e intermitentes vías de comunicación, dejados a su suerte y a sus fuerzas al ser histórica y prácticamente olvidados en los programas y presupuestos gubernamentales [...]”. 
co como una región propiamente dicha, pues se contaba con un sistema económico y político autoorganizado, con estructura industrial propia, división de trabajo peculiar y relativa estabilidad entre las bases de poder (Escobar y González de la Rocha, 1988: 34). ${ }^{17}$ Esa configuración regional se forjó entre los siglos XVI y XIX, pues si se acepta el argumento de Roberts (1980: 10), en el sentido de que muchos elementos de identidad se consolidan mediante las imposiciones que realiza un grupo social hegemónico, entonces en el sur de Jalisco hubo, hasta el siglo XIX, elementos para por lo menos poder hablar de una región que mantenía su organización socioeconómica bien definida, al haber una élite regional que a la vez que preservaba la unidad interna, servía como intermediario de los intereses de la región en las relaciones con las fuerzas externas y con el Estado nacional (De la Peña, 1980: 38).

Paradójicamente, la fortaleza de las unidades económicas regionales en esa época se basaba en las condiciones geográficas irregulares que dificultaban el acceso desde otras regiones y que permitieron a las empresas locales mantener un mercado protegido, donde se desarrollaba una dinámica actividad comercial gracias al oficio de la arriería (Vallejo, 1991: 32). ${ }^{18}$ Incluso, estas circunstancias permitían que determinados productos de la región pudieran ser exportados a ciudades como Guadalajara, o a otros estados, principalmente del centro del país.

Sin embargo, a partir de la segunda mitad del siglo XIX, una serie de fenómenos obstaculizaron la articulación regional.

El primero fue la construcción del ferrocarril Manzanillo-Guadalajara, inaugurado en 1901, obra que influyó en la desarticulación de la región en varios sentidos:

a) En primer lugar porque se construyó en la zona del valle de Sayula y de Zapotlán, lo que ocasionó que muchos pueblos -como los ubicados en las sierras de Tapalpa y El Tigre- quedaran aisla-

${ }^{17}$ Además, otro elemento que abonaba en favor de esa autonomía regional era la ambigüedad jurídico-política, pues a decir de José María Muriá (1976 y 1977), hasta antes de la Independencia de México, el sur de Jalisco era dependencia tanto de la Nueva España (no de la Nueva Galicia), como del obispado de Michoacán y de la provincia franciscana de Santiago de Xalisco. Igualmente, Leticia Vallejo (1991:32) señala que en esas fechas, el sur de Jalisco (conjuntamente con la villa de Colima) se regía por la jurisdicción política de Guadalajara, pero por la jurisdicción eclesiástica de Valladolid.

${ }^{18}$ Igualmente, otro factor que favoreció la actividad económica -principalmente comercial- en esa región, fue el hecho de que a raíz de la guerra de Independencia, se cambiara el puerto de llegada de Acapulco a Tepic, de los productos que arribaban a México por la costa del Pacífico (De la Peña, 1979). 
dos. Ello propició, por un lado, que las industrias regionales allí instaladas (que, por cierto, eran las más florecientes en esa época, como la Ferrería de Tula o la fábrica de papel La Constancia, ubicadas en la sierra de Tapalpa) quedaran en desventaja competitiva frente a las importaciones que necesariamente llegarían de otras partes del país, orillándolas a su posterior quiebra.

Por otro lado, muchos de los pueblos aislados poco a poco fueron perdiendo contacto con los mejor comunicados, diferenciándose más tanto en su desarrollo económico como en los rasgos culturales. Si uno de los aspectos que permiten la conformación de una identidad regional, es que los pueblos sean más o menos homogéneos en sus niveles de desarrollo económico, social y político, en el sur de Jalisco esto no sucedió durante el siglo Xx. Así, mientras los niveles de bienestar en Los Altos (lo cual es un indicador de desarrollo) son actualmente similares en todos los municipios, en el sur existe una gran heterogeneidad (INEGI, 2001). Así, el atraso que en este sentido tienen municipios como Atemajac de Brizuela, Jilotlán, Quitupan, Santa María del Oro, Tolimán y Zapotitlán de Vadillo, contrasta de manera notable con los niveles de bienestar medios y altos que alcanzan municipios como Zapotlán El Grande, Tamazula, Sayula, Tuxpan, Zacoalco o Zapotiltic (Macías, 2005).

b) El ferrocarril también afectó la capacidad competitiva de otras industrias pequeñas de la región que hasta el siglo XIX habían permitido el fortalecimiento de la oligarquía económica regional, pues facilitó la importación de muchas mercancías gracias a la disminución considerable de los costos de transporte (De la Peña, 1977: 20). Los productos importados -provenientes principalmente de Guadalajara-, se fabricaban con una tecnología más avanzada que la usada localmente, lo que ocasionó la quiebra de muchas haciendas que tuvieron que ser vendidas a capitales foráneos (precisamente de Guadalajara), iniciándose con ello el desplazamiento de la oligarquía regional. Igualmente, las empresas transportistas locales que habían sido un importante factor de capitalización, fueron desplazadas por el ferrocarril.

En realidad, el ferrocarril fue sólo el factor detonante de un hecho estructural que tarde o temprano ocasionaría problemas a la economía regional. Las empresas locales pudieron sobrevivir mientras mantuvieron el mercado semicerrado, pero en cuanto se vieron obligadas a competir, sucumbieron irremediablemente, ya que la misma protección que les había ayudado durante todo el siglo XIX, también les dificultó la importación de tecnología avanzada. 
c) Finalmente, el ferrocarril vino a afectar el dinamismo comercial de algunas poblaciones que en esas fechas tenían una posición estratégica en la economía regional, como fue el caso de Sayula, donde hasta el siglo XIX abundaban las bodegas que recibían y reexpedían por medio de la arriería las mercancías de la región a Guadalajara, San Gabriel, Tapalpa, Autlán, etc. (Munguía, 1987: $5)$. Todavía a finales de ese siglo, Sayula era un verdadero almacén donde se guardaban todos los productos que provenían de las serranías cercanas para ser conducidos a Guadalajara y otros lugares, y existían casas de comercio cuya influencia se extendía hasta la costa del estado, lo que permitió que la población de Sayula prácticamente se duplicara, al pasar de 6,561 habitantes en 1867 a 13,662 en 1885 (Munguía, 1998: 191).

Pero con la construcción del ferrocarril, el comercio de Sayula perdió mucha de su importancia ante las facilidades que éste generó para el transporte de mercancías entre Guadalajara y Manzanillo, obviando a la estación de Sayula. Además, la disminución de los costos de transporte hacia poblaciones externas a la región para conseguir diversas mercancías, minó el peso que como centros comerciales regionales tenían determinados pueblos como el propio Sayula.

Pero si el ferrocarril y las posteriores vías de comunicación hirieron de muerte a la oligarquía local, el tiro de gracia lo dio la inserción de México y la región en un nuevo modelo económico internacional de monopolios que era totalmente contrario al proyecto de desarrollo de las industrias locales. A partir de esas fechas, las estrategias económicas regionales debían organizarse en función de su articulación a los mercados nacional e internacional.

Además, como los empresarios locales no pudieron por sí mismos impulsar ese cambio, ni tuvieron las redes sociales necesarias con los intereses extralocales para hacerlo, se vieron obligados a aceptar, a mediados del siglo xx, la paulatina conformación de nuevas grandes empresas surgidas del proyecto de desarrollo nacional, que aprovecharon la riqueza de recursos naturales de la región pero con intereses en muchas ocasiones ajenos a la misma. Los principales casos fueron el ingenio de Amatitlán (que se formó con capitales locales en conjunto con empresarios de Guadalajara y que fracasó en 1950), el Ingenio Tamazula (inicialmente formado por los empresarios locales Salvador y Alvino Mendoza, pero que terminó necesitando capital de la Ciudad de México para sobrevivir y después pasó a ser propiedad del grupo de Aarón Sáenz 
Garza), la fábrica de papel de Atenquique (formada por empresarios de Guadalajara, pero que después formó parte del gobierno federal y luego fue vendida en los años noventa al principal grupo industrial maderero nacional), la fábrica de cementos Tolteca (perteneciente al grupo trasnacional Portland), así como la fábrica de cementos Guadalajara.

A partir de ello, el sur de Jalisco pasó a depender de Guadalajara y de los capitales extralocales, con empresas que frecuentemente funcionaron como enclaves. ${ }^{19} \mathrm{~A}$ la vez, muchas localidades se fueron sumiendo en el atraso económico, con poblaciones que presentaron un panorama de pauperización, pobreza rural, así como tierras abandonadas, deterioradas o apropiadas por agentes externos (De la Peña, 1999: 42). Incluso Ciudad Guzmán, centro de la vida económica regional, en los últimos años del siglo xx perdió competitividad en relación con otras ciudades medias de Jalisco, como Puerto Vallarta, Lagos de Moreno, Tepatitlán u Ocotlán (Macías, 2004).

Pero la inserción de la región al modelo nacional e internacional que obstaculizaba las iniciativas locales, no sólo tiene connotaciones económicas, sino que también respondió a un interés político del Estado revolucionario de crear un proyecto nacional que se antepusiera a los regionalismos. La base para tal postura era que, al persistir las fuerzas regionales que se anteponían al ideario nacional, los derechos de los ciudadanos se subordinaban a los intereses de grupos particulares aglutinados alrededor del caudillo o cacique.

Como ya mencioné, hasta el siglo XIX el Estado nacional manifestaba una gran debilidad frente a las élites regionales que actuaban siempre en defensa de sus intereses (De la Peña, 1988: 36). En el fondo, esa debilidad recaía en una ausencia de conciencia nacional que a su vez se derivaba, a decir de Xavier Guerra y Fernando Escalante (mencionados por Zárate, 1997: 260), de que el mexicano en general mantiene mucho más apego a los

${ }^{19}$ Los enclaves, concepto desarrollado por la economía política durante las décadas de 1970 y 1980, se definen como polos de explotaciones económicas encabezados por un principal de exportación, que dependen en gran medida de las condiciones dictadas en otras regiones (de las que se es enclave), sin generar repercusiones y eslabonamientos al interior de la zona productora. "Los encalves tienen una intensa actividad económica pero operan aislados del contexto regional, sin derramar beneficios considerables sobre su entorno geográfico. Los empresarios que fundan y conservan tales enclaves no residen ni están interesados en la región: son parte de grupos centralistas y sus ganancias se reinvierten en actividades que consolidan la hegemonía del centro" (De la Peña, 1977: 2-3). 
grupos que se encuentran estrechamente vinculados a él, que a los grupos institucionales como el Estado.

Por eso, el Estado surgido de la Revolución, forjado por élites políticas e intelectuales urbanas, lo primero que se propuso fue crear una conciencia nacional que lo fortaleciera, con la premisa de que su discurso sería modernizante y racional, en tanto que el discurso local, fundado en la apariencia comunitaria, era arcaizante y frenaba al desarrollo del país (Zárate, 1997: 45).

Pero tal sustitución de las grupalidades por el individualismo necesario en una economía capitalista, no podía lograrse sólo por decreto, ya que aquéllas se encontraban profundamente arraigadas en la cultura de los pueblos, además de que las enormes diferencias socioculturales, educativas y económicas existentes en la primera mitad del siglo xx, hacían prácticamente inalcanzable el desarrollo del Estado capitalista moderno sobre las bases de la democracia política.

Ante tal situación de fuertes contrastes, el Estado nacional revolucionario tuvo que imponerse mediante decisiones centralistas, autoritarias y antidemocráticas, así como por medio del control de los recursos estratégicos. Además, la búsqueda de la cohesión social se dio sobre la base de exaltar el nacionalismo imaginario y discursivo, conseguido no por la práctica diaria, sino mediante la constante imposición disfrazada, que utilizó todos los mecanismos a su alcance (desde la escuela, los medios masivos de comunicación, hasta las diversas formas artísticas de interacción social). Era pues un artilugio que pretendía uniformizar la tremenda heterogeneidad existente, una serie de conceptuaciones simplistas que dejaban de lado la complejidad histórica de pueblos y grupos sociales.

Por otro lado, si la Revolución reclamaba la reivindicación de las masas, pero el futuro del Estado se forjaba en su compromiso con el proyecto nacional capitalista, entonces tal contradicción sólo pudo ser solucionada mediante un complejo mecanismo de mediación política estable, que no era democrático, pero aseguraba, con formas no capitalistas de organización populista, que el proceso económico siguiera su curso (Bartra, 2002: 13). ${ }^{20}$ Ello no quiere decir que tales políticas siempre fueran en beneficio de las élites económicas involucradas en el modelo capitalista.

\footnotetext{
${ }^{20}$ De hecho, la persistencia de localismos afianzados en la preferencia de muchos actores por los grupos cercanos, fue una de las razones más importantes que obligaron al Estado a acudir a los caciques locales como intermediarios entre el proyecto nacional y los intereses locales, constituyéndose esta mediación en un mecanismo muy importante de articulación del sistema político y económico global (De la Peña, 1988: 31).
} 
Por principio de cuentas, las políticas públicas son sumamente diversas y en algunos momentos hasta contradictorias, puesto que el Estado es un campo de poder donde concurren muchos agentes heterogéneos que en el ejercicio de su función, persiguen sus propios intereses o visiones de las cosas. De esta manera, mientras en algunos periodos la mayoría de las políticas impuestas se enfocaron a consolidar la estructura capitalista con base en los grupos con mayor presencia nacional e internacional, en otras ocasiones, e incluso al mismo tiempo, se ejercieron otras que fueron opuestas a los intereses de los grupos de poder (Grindle, 1985, mencionado por Long, 2001: 46).

Además, aunque la planeación y construcción de las políticas corresponden a las más altas jerarquías en la escala de gobierno -donde hay todo un capital cultural y simbólico (conocimiento técnico administrativo de la situación) producto del propio ejercicio del poder-, son los mandos medios y la burocracia quienes las aplican, y ellos no actúan de manera mecánica, sino que hacen uso de su libertad para aplicar la política conforme a sus intereses personales y de grupo. Por eso, la instrumentación de una política es el resultante de la negociación permanente que se lleva en cada localidad y momento, entre los actores del Estado en sus distintos niveles, y entre éstos y los grupos sociales receptores.

Aun así, en términos generales sí podemos hablar de que la política del Estado en la primera mitad del siglo xx, se enfocó a fortalecer el proyecto nacional capitalista, lo que para el sur de Jalisco implicó el apoyo desde el gobierno federal a las empresas monopólicas que se establecieron allí, en detrimento de las iniciativas locales.

En resumen, la apertura de vías de comunicación, el ingreso de empresas comprometidas más con el modelo internacional capitalista que con los intereses regionales, y la implantación del proyecto de identidad nacional, acabaron por desplazar a las élites locales y desarticular la economía del sur de Jalisco. Esa desarticulación fue, a decir de Guillermo de la Peña (1977: 38), una de las razones por las que ese territorio perdió buena parte de las características que lo hacían ser una región:

En el siglo xx surge una nueva combinación territorial que relaciona directamente las áreas agrícolas del sur de Jalisco con sistemas urbanos, comerciales, industriales y políticos más amplios sin la necesidad de una élite regional mediadora. Más aún, en la nueva pauta organizativa las relaciones de las áreas territoriales del sur de Jalisco con los espacios de la sociedad nacional e internacional son más importantes incluso que 
las relaciones de aquellas áreas entre sí. No puede, por tanto, hablarse propiamente de una región en el sur Jalisco en el presente siglo.

Además, la reconfiguración del espacio regional de acuerdo con las pautas organizativas del mercado nacional e internacional, profundizó un proceso que históricamente ya venía dándose en el sentido de que ese territorio no es un mosaico cultural compacto perfectamente identificable y diferenciable de las demás regiones, sino una variedad de manifestaciones culturales de diversa índole, construidas sobre fuertes y atomizadas identidades locales (Vaca, 2003: 56).

Ahora bien, a pesar de lo anterior, la imposición del modelo de desarrollo centralizado no implicó que los actores locales se mantuvieran como sujetos pasivos y receptivos a las fuerzas externas. Por el contrario, la población buscó aprovechar en su beneficio los cambios que se dieron, adaptándolos y reconstruyéndolos de acuerdo con su propia realidad. Así, la identidad nacional reconstruyó las identidades locales, pero también se vio reconstruida por éstas, en un proceso dinámico no exento de conflictos y enfrentamientos (Zárate, 1997: 291).

En el sur de Jalisco, ese proceso de asimilación provocó que ambas identidades compartieran la mayoría de sus elementos, de manera que la integración de la región al proyecto nacional pudo darse casi sin conflictos. Sin embargo, en otros casos no sucedió así, y hubo un constante roce entre lo local y regional con lo nacional, lo cual se manifestó -y aún continúa haciéndolo- en el rechazo permanente que muchos habitantes de ese territorio han expresado a diversas decisiones centralizadas, y en el constante esfuerzo de diferentes grupos sociales para mantener ciertas autonomías. Así, la identidad nacional fue bien recibida y aceptada en tanto sirvió a los intereses de los actores locales para obtener recursos por ellos necesitados. Sin embargo, una vez que ésta dejó de ser funcional -cuando el Estado neoliberal se alejó del modelo nacionalista-, entonces aparecieron de nuevo los localismos y regionalismos siempre presentes, aunque no abiertamente manifiestos en una sociedad donde el apego a las grupalidades nunca ha desaparecido.

\subsection{El resurgimiento de las identidades locales}

Los cambios recientes en la vida política y económica nacional -caracterizados por el cuestionamiento tanto a los proyectos de desarrollo centralizados que fueron gérmenes de clientelismo y corrupción, como a la legitimidad de las instituciones políticas 
formales surgidas del Estado desarrollista revolucionario-, así como la necesaria incorporación mexicana al mundo globalizado, la aparición de un Estado de corte neoliberal y la incipiente estructura democrática que por lo menos en algunos casos debilitó el poder autoritario de ciertos actores sociales, han favorecido el resurgimiento de las identidades locales, ${ }^{21}$ las cuales se presentan con un fundamento histórico pero redefinidas de acuerdo con las nuevas relaciones mantenidas en el ámbito local, regional, con el Estado nacional y con el contexto internacional. Es decir, muchos grupos sociales que nunca dejaron de considerarse distintos, hoy vuelven a hacer abiertamente manifiesta su diferencia y su derecho a ello.

Pero si el panorama nacional permite que aparezcan nuevamente en la palestra las identidades locales, el contexto internacional también fortalece este fenómeno, pues, paradójicamente, la globalización, lejos de alcanzar la homogeneidad cultural con la preponderancia de Occidente, lo que ha permitido es una dinámica en la que se traslapan procesos que hacen a los individuos y a los grupos sociales cada vez más multiculturales, pero que también recurren cada vez más al rescate de aquellos elementos que los distingan de los demás. Como señala Anthony Giddens (1991):

En la medida en que la tradición pierde su valor, y en que la vida diaria es reconstruida en términos de contrapunto dialéctico entre lo local y lo global, los individuos se ven obligados a negociar sus estilos de vida considerando múltiples opciones. Por supuesto, hay también influencias estandarizadoras, principalmente con la forma de la "mercaderización" de la vida, puesto que la producción y distribución capitalistas forman el componente central de las instituciones modernas. Sin embargo, a causa de la apertura de la actual vida social, de la pluralización de los contextos del comportamiento y de la diversidad de las autoridades, la elección de los estilos de vida resulta cada vez más importante

\footnotetext{
${ }^{21}$ Hablo de resurgimiento porque aun cuando el Estado nacional impusiera ciertos cánones, sobre todo para el acceso a determinados recursos, las tradiciones no se borran de un día para otro, sino que se sostienen y sólo se van modificando como resultado de la dinámica propia de la cultura. Así, por ejemplo, una tradición que todavía hoy se vive en muchos pueblos del sur de Jalisco, es la de velar a los muertos en las casas, vestir de santo o virgen al difunto si es niño o niña, acompañar a pie al cortejo funerario hasta el cementerio, cargando el féretro en los hombros familiares o amigos (pues, de lo contrario, se ofende al difunto por no hacer un último sacrificio en su memoria), o celebrar una misa o rosario durante los nueve días siguientes a la muerte del personaje. En algunos pueblos prevalecen tradiciones muy localizadas que son reflejo de la importancia mayúscula que tiene la cultura indígena, como en el caso de Tuxpan, donde al final del novenario se celebra una comida en agradecimiento a las personas por haber acompañado en el duelo, pero tal comida adquiere características de fiesta.
} 
en la constitución de una identidad y en el desarrollo de nuestras actividades diarias.

De esta forma, los valores que se identifican con los nuevos tiempos globalizados tienen que ver con la preferencia por la capacidad de optar, por la iniciativa personal, la creatividad y la diferencia, así como por lo transitorio, particular y contingente, donde las raíces culturales, más que buscarse en la legitimidad de un proyecto social, ahora deben identificarse en la pluralidad de nichos, en lo particular y local, así como en lo electivo (Tomassini, 2000: 81).

Pero la construcción de los estilos de vida no se da en un ambiente de libertad absoluta como el que pregona el individualismo metodológico, ni en un marco de equidad en el que cada individuo o grupo pueda legitimar su propio proyecto de desarrollo social. Por el contrario, en un mundo donde subsisten e incluso se fortalecen las injusticias, desigualdades y dominaciones que privilegian a determinados grupos y naciones, muchos de los perjudicados nuevamente recurren a sus propios grupos e identidades culturales locales, las cuales se fortalecen aun cuando puedan ser contrarias y hasta agresivas al proceso global.

El resurgimiento de las identidades locales es una consecuencia del momento histórico que se vive mundialmente. Para las localidades semiurbanas o rurales como las que existen en el sur de Jalisco, el recurrir de nuevo a sus propias categorías identitarias, más que significar un rechazo a la necesidad de integrarse en esta nueva circunstancia mundial o no reconocer el dinámico proceso de hibridación entre las culturas actuales, conlleva hacerlo con base en los propios fundamentos culturales que permitan asumir los retos de la modernización, pero con un sentido propio (Zárate, 2003: 45).

Ese proceso se refleja en el avance de ciertas reivindicaciones locales, como la restauración de los nombres originales de los pueblos en vez de aquellos impuestos por el Estado nacional: San Gabriel se reivindica luego de muchos años de ser llamado Venustiano Carranza; Zapotlán El Grande logra recobrar su nombre, quedando sólo la cabecera municipal como Ciudad Guzmán; los habitantes del otrora Gómez Farías consiguen que nuevamente éste se llame San Sebastián del Sur, cosa que también logran los habitantes de Santa María del Oro, anteriormente llamada Manuel M. Diéguez.

Igualmente, las reivindicaciones locales se manifiestan en la reaparición de ciertas fiestas autóctonas que habían sido opacadas, como la de los Naturales en Sayula, los danzantes de San 
Cristóbal del Barrio Alto de Mazamitla o la Cofradía de los Moros en Zacoalco, que no sólo rescatan la cultura local forjada desde tiempos prehispánicos, sino que también ponen de manifiesto la exigencia de determinados grupos sociales para ser reconocidos como parte de la diversidad comunitaria.

\subsection{Reconfiguración de las identidades locales}

Si bien es cierto que en los últimos años hay un resurgimiento de algunas manifestaciones identitarias locales, éste también ha ido acompañado por procesos de hibridación cultural, lo que en un principio pareciera ser una contradicción, pero que más bien se trata de dos caras opuestas de un mismo fenómeno que hoy se está viviendo más que en otros tiempos. Ello es así porque las identidades, al no ser estáticas, no sólo se alimentan de las costumbres, sino que también se van reconstruyendo en la experiencia diaria, siendo que tal experiencia hoy es mucho más compartida con lo que pasa en otros lugares del mundo.

En el sur de Jalisco, además de la implantación del proyecto nacional, varios fenómenos recientes derivados del cambio económico han transformado más aún a las identidades. El de mayor importancia es la emigración de muchos de sus habitantes hacia otras zonas del país y del extranjero, fenómeno que se intensificó durante el último cuarto del siglo xx, como resultado de la pérdida de oportunidades económicas en los municipios de origen. Familias completas han dejado de vivir en el sur de Jalisco, llevándose con ellas una identidad que poco a poco se va perdiendo con el paso de las generaciones, aun cuando los hijos de los emigrados en muchas ocasiones suelen regresar al lugar de origen de sus padres incluso dos o tres generaciones después, para identificarse con las tradiciones de sus ancestros.

Igualmente, los que se quedan reciben el impacto cultural de quienes emigran temporalmente, pues el continuo ir y venir de personas que se van a trabajar principalmente a Estados Unidos, ha derivado en la modificación drástica de algunas de las pautas culturales locales, ya que los migrantes (llamados hijos ausentes), suelen regresar a sus poblaciones por lo menos en ciertas temporadas, trayendo nuevas prácticas que asimilan sobre todo los jóvenes. Es común encontrar música, ropa, vehículos y formas de diversión 'americanizadas', sobre todo a medida que el pueblo es más representativo como expulsor de mano de obra.

Por otro lado, la mayor presencia de los medios masivos de comunicación y la llegada de nuevas actividades económicas y 
empresas provenientes de otras partes de México y el extranjero, también ha generado la proliferación de prácticas importadas que se identifican más con una modernidad derivada de la globalización que con las tradiciones locales. Ponemos como ejemplo el caso de Sayula y las empresas hortícolas originarias principalmente de Sinaloa, que empezaron a producir en ese municipio a partir de los años ochenta. Con la llegada de esta actividad productiva, se dieron algunos cambios importantes en las prácticas laborales locales.

Uno de esos cambios fue la incorporación masiva de la mujer al mercado de trabajo. En Sayula, como en muchas de las poblaciones semiurbanas mexicanas, tradicionalmente la mujer se había dedicado a las tareas del hogar, y en muy pocas ocasiones ingresaba al mercado laboral. Sin embargo, en los empaques de las empresas hortícolas, el trabajo femenino era mayoritario, de manera que si bien al principio éste era ocupado casi exclusivamente por trabajadoras que las propias empresas traían de sus lugares de origen, pronto empezó a haber demanda de mano de obra local para las tareas menos especializadas, siendo ése el momento en el que se contrató a las primeras mujeres sayulenses, quienes después invitaron a sus familiares y amigas para que también fueran contratadas. No obstante, en un principio ese proceso no se dio de manera fluida, pues hubo rechazos, principalmente por parte de los padres de familia, para enviar a sus hijas jóvenes, de entre 15 y 20 años a trabajar, tanto por esa falta de costumbre de que la mujer trabajara, como por seguridad, pues, según ellos, los empaques tenían mala fama, pues se decía que en ellos se generaba mucho desorden sexual y promiscuidad entre los empleados.

Sin embargo, la difícil situación económica por la que atravesaban muchas familias y el conocimiento de que varias muchachas, hijas de vecinos, ya estaban trabajando en los empaques, hizo que los padres paulatinamente accedieran a que sus hijas laboraran, como una forma de complementar el ingreso de la familia o, por lo menos, para que ellas tuvieran dinero para costearse sus propios gastos. Incluso, más adelante accedieron a que también las esposas fueran a los empaques, sobre todo al de la empresa Santa Anita, que se encontraba dentro de la ciudad, cambiando definitivamente una práctica que hoy es casi una reminiscencia en la medida en que más mano de obra femenina se incorpora al trabajo asalariado.

Otro cambio en las tradiciones culturales locales se dio por las jornadas de trabajo. El horario de 8:00 a 16:00 o 17:00 
horas propuesto por las empresas hortícolas, era muy distinto al de la rutina de trabajo al que la gente del campo estaba acostumbrada en Sayula, donde se laboraba generalmente de 7:00 a 12:00 horas, para en la tarde tener tiempo de trabajar en la propia parcela o realizar otras actividades. De hecho, este cambio de horario fue una de las razones por las que al principio hubo más resistencia de la población local para emplearse en el trabajo de campo de ese tipo de empresas, por lo que éstas tuvieron que contratar a jornaleros indígenas provenientes principalmente del sur del país.

La modificación del horario laboral impactó en una de las prácticas culturales más arraigadas en las familias mexicanas: la convivencia a la hora de la comida, siendo ése uno de los momentos más importantes donde las familias se encuentran y comparten las experiencias del día. Sin embargo, ahora tanto los trabajadores del campo como los del empaque, generalmente cuentan sólo con una hora para comer, por lo que les resulta prácticamente imposible trasladarse a su casa si viven lejos del área de trabajo. Por ello, esa costumbre mexicana ahora está siendo ahora sustituida por la llamada hora de "lonchear", al estilo de los trabajadores norteamericanos o europeos (Brandt, 2002: 191), con repercusiones como la pérdida de relación social que se da al interior de las familias. Igualmente, en el empaque la jornada de trabajo suele ampliarse hasta las 2:00 horas en épocas de cosecha, lo que modifica otra tradición cultural de los pueblos de México, como es el que las mujeres estuvieran en sus casas en las primeras horas de la noche, pues lo contrario se consideraba un indicador de libertinaje.

En resumen, los fenómenos migratorios en diferentes vías, así como la influencia ejercida por los medios masivos de comunicación, originaron la reconfiguración de varios elementos que forman las identidades locales, en un proceso que es consecuencia lógica de la dinámica provocada por la globalización. Independientemente de si algunos de esos cambios son positivos o negativos para la vida local, la realidad es que ponen de manifiesto, en el sur de Jalisco, como en prácticamente todo el mundo, que en la conformación de las identidades culturales, como dice Néstor García Canclini (2004: vI), hoy más que antes parece muy iluso intentar "delimitar identidades locales autocontenidas o que intenten afirmarse como radicalmente opuestas a la sociedad nacional o la globalización”.

Ahora bien, esa dinámica de intercambios culturales, a la vez que reconfigura las identidades locales, dificulta más el poten- 
cial resurgimiento de una identidad regional en el sur de Jalisco, sobre todo por las barreras que existen y que se reseñaron en este trabajo.

\section{Conclusiones}

Las identidades colectivas se constituyen de elementos culturales que han sido internalizados en la subjetividad de los individuos permitiéndoles identificarse con un grupo social, así como distinguirse de otros. Sin embargo, las identidades no son estáticas, constantemente se construyen y reconstruyen de acuerdo con los retos que se le presentan a las sociedades en un permanente esfuerzo de aprendizaje y reaprendizaje de los individuos por medio de las acciones colectivas.

Ahora bien, si las identidades culturales no existen en forma pura, sino que se reconstruyen con constantes intercambios, en el contexto actual de los procesos de globalización, las migraciones masivas y el desarrollo de los medios de comunicación, lo que hoy se observa son complejos modelos híbridos en los que pareciera ya no ser muy relevante hablar de identidades territorialmente definidas. Incluso, hoy más que antes debemos hablar de identidades que más que corresponder con un espacio geográfico en que se comparte un universo simbólico unitario, tienen que ver con la pluralización de los mundos de vida; es decir, con grupos específicos de personas que comparten algún patrón común, sea éste de tipo étnico, de género, de clase, político, económico, etc., y ello hace mucho más complejo el tema de las identidades y las repercusiones que tienen en la solución de los problemas que día a día tienen los actores sociales, pues "la dinámica de la identidad moderna es cada vez más abierta, proclive a la conversión, exasperadamente reflexiva, múltiple y diferenciada” (Sciolla, 1983, en Giménez, 2000b: 18).

Con todo, y a pesar de la aparente globalización multicultural a la que hoy estamos expuestos, las identidades referidas a un territorio siguen funcionando desde el momento en que los actores sociales interpretan de distintas formas (de acuerdo, precisamente, con sus marcos culturales) un mismo mensaje. Además, las identidades culturales continúan siendo de vital importancia en la vida de las personas y las colectividades, pues, como dice Edmond Lipiansky (1992: 41), "aún inconscientemente, la identidad es el valor central en torno al cual cada individuo organiza su relación con el mundo y con los demás sujetos”, de manera 
que "únicamente mediante el acceso a una cultura compartida, las personas pueden tener acceso a una serie de opciones significativas" (Kymlicka, 1996: 121).

Incluso desde un punto de vista económico, donde la globalización es más evidente, el conocimiento local se convierte en una de las principales herramientas para las ventajas económicas, al constituir una fuente importantísima de información y aprendizaje que no puede ser difundida a través de los medios formales de comunicación, sino que por su complejidad requiere de mecanismos de confianza y entendimiento que sólo se logran con las experiencias generadas por los intercambios informales cara a cara (Amin, 1998: 75; Leamer y Storper, 2001: 1).

El conocimiento local que es dinámico, disperso y discontinuo al generarse en la experiencia diaria de la gente y sus necesidades, hace inviable su fijación y codificación en libros o manuales para que cualquiera que se interese en él, pueda acceder al igual que lo hace con el conocimiento científico (Ellen y Harris, 2000: 16). En este contexto, la identidad cultural resulta básica para que puedan transmitirse los códigos sobre los que se establece ese conocimiento local.

Ahora bien, si las identidades territoriales siguen siendo de gran importancia para el desarrollo de las personas, dos preguntas saltan a la vista. Primero, ¿qué importancia pueden tener las identidades locales respecto a una identidad nacional? Para responder a ello, habrá que considerar lo dicho por Tzevetan Todorov (1993, en Kymlicka, 1996: 116), en el sentido de que "la cultura no es necesariamente nacional (e incluso sólo excepcionalmente lo es). Es antes que nada, la propiedad de una región, o de una entidad geográfica incluso menor”. Es decir, la identidad de una persona se forma principalmente de la cultura que recibe del entorno inmediato donde convive y cumple determinados roles, aun cuando el desarrollo de los medios de comunicación hagan más posible la conformación de patrones identitarios en las llamadas comunidades imaginadas, sean éstos un Estadonación o, también, grupos trasnacionales que defienden determinados derechos (como los movimientos ambientalistas o feministas).

Lo anterior no quiere decir que las identidades nacionales no sean muy importantes, sobre todo en el actual mundo globalizado, donde los países requieren mantener ciertos patrones culturales diferenciadores que les permitan aprovechar las ventajas que ofrece la globalización, así como protegerse de los riesgos que la misma conlleva. Pero, al mismo tiempo, la propia dinámica actual 
que perfora las fronteras nacionales, es lo que ha hecho que las identidades locales y de grupos pequeños y específicos adquieran un significado mucho más trascendente para las personas.

En segundo lugar, ¿qué importancia tiene hablar de identidades regionales respecto de las locales? Aquí habría que considerar que mientras un espacio local es por lo general pequeño y limitado, una región ofrece evidentemente muchas más posibilidades de intercambios socioculturales. Sin embargo, si existe una identidad regional débil, ello tendrá repercusiones en aspectos como, por ejemplo, los intercambios económicos, de manera que si una persona vive en un espacio geográfico en donde los habitantes de los pueblos circunvecinos son vistos como extraños y, no sólo eso, sino también como pueblos que históricamente han estado en constante lucha y se han visto envueltos en diferentes enfrentamientos, es lógico que lo que predomine en las relaciones entre ellos sea la desconfianza, el aumento en los costos de transacción en cualquier intercambio que se realice (y que, obviamente, son muchos por la propia cercanía geográfica), la necesaria formalización legal de las relaciones económicas, así como el desinterés por ejecutar obras de mutua cooperación o por formar alianzas que incrementen el poder en las negociaciones que se sostengan con actores externos a la región.

Como consecuencia de todo ello, disminuye la velocidad con la que se realizan los intercambios. A menor velocidad, menos intercambios y de más baja calidad y, por lo tanto, menos posibilidades de crecimiento y desarrollo económico regional. Esto no quiere decir que no existan y se acrecienten relaciones de confianza entre personas o grupos de personas de distintas poblaciones, pero éstas estarán concentradas en determinadas redes o nichos sociales específicos, y al no salir al resto de la región, disminuye su poder para impactar a toda una comunidad.

Ahora bien, en este trabajo mencioné que en el caso del sur de Jalisco un elemento importante que dificulta la consolidación de una identidad regional, es la diferenciación social intra e inter pueblos, proveniente de aspectos étnicos, de clase, etc. Cuando ésta se incrementa, hay un mayor extrañamiento cultural entre los actores individuales y colectivos de la misma región, donde cada grupo defiende intereses particulares, de manera que son menos los elementos compartidos. Si bien en algunos casos logran conciliarse las diferencias en determinados actos simbólicos (como la fiesta de San José, en Zapotlán), en otros no llegan a superarse, e incluso se agravan. 
Esta situación se complica si en la región no existen grupos hegemónicos que, mediante su ascendencia en la región, logren cohesionar las diversas vivencias en un proyecto compartido.

En ese contexto, aquí he intentado demostrar mi hipótesis de que en el sur de Jalisco, si bien las identidades locales son fuertes (hay un gran orgullo de las personas por pertenecer a su pueblo) a pesar de las adaptaciones que evidentemente han tenido que sufrir, como consecuencia, primero de la irrupción del proyecto de desarrollo nacional que pretendió de alguna forma hacer más homogénea la cultura de los distintos pueblos de México, y después, de la globalización y los procesos migratorios, tal fortaleza no se manifiesta en una identidad regional debido, primeramente, a la alta diferenciación social existente en la región, tanto entre los municipios y pueblos como al interior de éstos, y, en segundo lugar, al debilitamiento de los grupos hegemónicos regionales y su alta dependencia de fuerzas extralocales. De esta forma, el "sureño" se convierte casi exclusivamente en una ilusión y no en un término de identificación, como sucede con el “alteño" en la región noreste de Jalisco.

\section{Bibliografía}

Amin, Ash (1998), "Una perspectiva institucionalista sobre el desarrollo económico regional”, Revista Economiaz, 41: 68-89.

Anderson, Benedict (1993) [1991], Comunidades imaginadas. Reflexiones sobre el origen y la difusión del nacionalismo, FCE, México.

Arreola, Juan José (1992) [1963], La feria, Joaquín Mortiz, México.

Barragán, Esteban (1991), "El rostro insólito del Sur de Jalisco", Revista Estudios Jaliscienses, agosto, 5: 55-60.

Barth, Fredrik (1976), Los grupos étnicos y sus fronteras, FCE, México.

Bartra, Roger (2002), "Prólogo", en Roger Bartra, Anatomía del mexicano, Plaza \& Janés, México, pp. 11-21. 
Beck, Ulrich (2001), "Vivir nuestra propia vida en un mundo desbocado: individualización, globalización y política", en Will Hutton y Antony Giddens, En el limite. La vida en el capitalismo global, Tusquets, Barcelona, pp. 233-245.

Brandt, Deborah (2002), Tangled Routes. Women, Work, and Globalization on the Tomato Trail, Garamond Press, Ontario.

Castolo, Fernando (2004), Historia hecha tradición. Zapotlán El Grande, ICHTHYs, Zapotlán El Grande.

De la Peña, Guillermo (1977), "Industrias y empresarios en el sur de Jalisco: notas para un estudio diacrónico", en Guillermo de La Peña et al., Ensayos sobre el sur de Jalisco, Centro de Investigaciones Superiores INAH-cuadernos de la Casa Chata, México, pp. 1-24.

De la Peña, Guillermo (1979), "Empresarios en el sur de Jalisco: un estudio de caso en Zapotlán El Grande”, en Guillermo Beato et al., Simposio sobre empresarios en México. II: Intermediación. Fracciones étnicas de clase. Contextualización regional, Centro de Investigaciones Superiores del INAH-cuadernos de la Casa Chata, México, núm. 22, México, pp. 47-84.

De la Peña, Guillermo (1980), "Evolución agrícola y poder regional en el sur de Jalisco", Revista Jalisco, núm. 1: 38-55.

De la Peña, Guillermo (1988), “Poder local, poder regional: perspectivas socioantropológicas", en Jorge Padua y Alain Vanneph (coords.), Poder local, poder regional, El Colegio de México, México, pp. 27-56.

De la Peña, Guillermo (1991), "Rituales étnicos y metáforas de clase: la fiesta de San José en Zapotlán el Grande”, Revista Estudios Jaliscienses, agosto, 5: 11-27.

De la Peña, Guillermo(1992), "Populism, Regional Power, and Political Mediation: Southern Jalisco, 1900-1980", en Eric Van Young (ed.), México's Regions. Comparative History and Development, Center for U.S.-Mexican Studies, University of California, San Diego, pp. 191-223. 
De la Peña, Guillermo (1994), "El Occidente y su cultura política contemporánea", en Ricardo Ávila, El Occidente de México en el tiempo, Universidad de Guadalajara, Guadalajara, pp. 215-223.

De la Peña, Guillermo (1999), "Las regiones y la globalización: reflexiones desde la antropología mexicana”, Estudios del Hombre, 10: 37-57.

Ellen, Roy y Holy Harris (2000), “Introduction”, en Ellen Roy et al., Indigenous Environmental Knowledge and its Transformations. Critical Anthropological Perspectivas, Harwood Academic Publishers, Australia.

Escobar, Agustín y Mercedes González-de la Rocha, (1988), Cañaverales y bosques. De hacienda a agroindustria en el sur de Jalisco, Gobierno del Estado de Jalisco, Guadalajara.

García Canclini, Néstor (2004), Culturas híbridas. Estrategias para entrar y salir de la modernidad, Grijalbo, México.

Giddens, Antony (1991), Modernity and Self-Identity: Self and Society in the Late Modern Age, Stanford University Press, Stanford.

Giménez, Gilberto (1987), La teoría y el análisis de la cultura, SEP-Universidad de Guadalajara-Comecso.

Giménez, Gilberto (1994), “Comunidades primordiales y modernización en México", en Gilberto Giménez y Ricardo Pozas (eds.), Modernización e identidades sociales, Instituto de Investigaciones Sociales UnAM-Instituto Francés de América Latina (IFAL), pp. 151-183.

Giménez, Gilberto (1996), “Territorio y cultura”, Conferencia magistral en la ceremonia de entrega de reconocimiento como Maestro Universitario Distinguido, Universidad de Colima, 8 de junio.

Giménez, Gilberto (2000a), “Identidades en globalización”, Espiral, vII (19): 27-48, Universidad de Guadalajara. 
Giménez, Gilberto (2000b), "Materiales para una teoría de las identidades sociales", en José Manuel Valenzuela (coord.), Decadencia y auge de las identidades, El Colegio de la Frontera Norte-Plaza y Valdés, México, pp. 45-78.

Gómez, Hidelgardo (2004), El sistema de cultivo de las hortalizas en el valle agrícola de Sayula, 1992-2004, documento mimeografiado.

González, Juan José (2001), Y mi pueblo Zapotlán se hizo Ciudad Guzmán, Amat, Zapopan.

Harvey, David (1990), The Condition of Postmodernity. An Enquiry into the Origins of Cultural Change, Blackwell, Cambridge.

INEGI (Instituto Nacional de Estadística, Geografía e Informática) (2001), Indicadores de bienestar, texto en <http://www. inegi.gob.mx/>.

Jiménez, Guillermo (1988) [1940], Zapotlán, Hexágono, Guadalajara.

Kymlicka, Will (1996) [1995], Ciudadanía multicultural, Paidós Ibérica, Barcelona.

Lameiras, José (1991), "El sur de Jalisco: asomos a una identidad", Revista Estudios Jaliscienses, agosto, 5: 61-71.

Larrain, Jorge (2004) [2000], Identidad y modernidad en América Latina, Océano, México.

Leamer, Edward y Michael Storper (2001), The Economic Geography of the Internet Age, Working Paper 8450, National Bureau of Economic Research, Cambridge, agosto.

Lipiansky, Edmond (1992), Identité et communication, Presses Universitaires de France, París.

Long, Norman (2001), Development Sociology. Actor Perspectives, Routledge, Londres y Nueva York. 
Macías-Macías, Alejandro (2001), "Atraso socioeconómico del sureste de Jalisco", Carta Económica Regional, eneromarzo, 75: 24-33.

Macías-Macías, Alejandro (2004), “Crecimiento económico y competitividad de las regiones. Las ciudades medias de Jalisco: el caso de Zapotlán El Grande", Región y Sociedad, septiembre-diciembre, 31: 39-82.

Macías-Macías, Alejandro (2005), "Brillante pasado, difícil presente e incierto futuro en la economía del sur de Jalisco", Carta Económica Regional, julio-septiembre, 93: 15-24.

Monsiváis, Carlos (2002) [1992], "La identidad nacional ante el espejo", en Roger Bartra, Anatomía del mexicano, Plaza \& Janés, México, pp. 295-301.

Munguía, Federico (1998) [1976], La provincia de Ávalos, Secretaría de Cultura del Gobierno de Jalisco, Guadalajara.

Munguía, Federico (1987), Esplendor, decadencia y actualidad de Sayula, Jal., Impresora Mural, Guadalajara.

Muriá, José María (1976), "La jurisdicción de Zapotlán el Grande del siglo XVI al XIX", Anales del Instituto Nacional de Antropología e Historia, $7^{\text {a }}$ época, vi (54).

Muriá, José María (1977), “Un cacique y su tradición: el sur de Jalisco”, Papers, 7: 169-180, Barcelona.

Olveda, Jaime (1994), "El Occidente de México en el siglo XIx: ¿Integración o desintegración?”, en R. Ávila (coord.), El Occidente de México en el tiempo, Universidad de Guadalajara, Guadalajara, pp. 215-223.

Roberts, Bryan (1980), "Estado y región en América Latina”, Relaciones, 4: 9-40.

Safa, Patricia (1988) [1979], Empresarios agrícola-ganaderos de Zapotlán, Universidad Autónoma Metropolitana, México.

Shadow, Robert (1994), "Los rancheros de occidente: Hacia un modelo de su organización comunitaria”, en Ricardo Ávi- 
la (coord.), El Occidente de México en el tiempo, Universidad de Guadalajara, Guadalajara, pp. 159-188.

Tomassini, Luciano (2000), "El giro cultural de nuestros tiempos", en Bernardo Kliksberg y Luciano Tomassini, Capital social y cultura: claves estratégicas para el desarrollo, Banco Interamericano de Desarrollo-Fondo de Cultura Económica, Buenos Aires, pp. 59-100.

Torres, Gabriel (2005), "Repensar el sur/sureste en Jalisco: comprender la pluralidad de proyectos de desarrollo y la heterogeneidad de actores e instituciones", conferencia presentada en el I Foro académico interinstitucional: Diálogos sobre el Sur de Jalisco: Actualidad y futuro del desarrollo, Universidad de Guadalajara-Instituto Tecnológico de Estudios Superiores de Occidente.

Torres Contreras, José de Jesús y Salvador Yánez Chávez (2003), Los tiempos olvidados. Historia, costumbres y tradiciones de Concepción de Buenos Aires, Jalisco 1500-2002, Gobierno del Estado de Jalisco-Ayuntamiento de Concepción de Buenos Aires, Guadalajara.

Vaca, Agustín (2003), "El sur de Jalisco: identidad e historia", Estudios Jaliscienses, 53: 51-59, agosto.

Vaca, Agustín, Mario Aldana, Jaime Olvida, Alma Dorantes, Frida Gorbach, Pablo Yankelevich, Cándido Galván, Angélica Peregrina y José María Muriá (1982), Historia de Jalisco. IV: Desde la consolidación del porfiriato hasta mediados del siglo Xx, Gobierno del Estado de Jalisco, Guadalajara.

Vallejo, Leticia (1991), "Los arrieros y las relaciones comerciales entre Colima y el Sur de Jalisco, 1810-1814”, Revista Estudios Jaliscienses, 5: 28-34, agosto.

Vázquez, Lourdes Celina (1997) [1993], Identidad, cultura y religión en el sur de Jalisco, El Colegio de Jalisco, Guadalajara.

Vizcaíno, Juan (1990), “Aspectos históricos de la feria”, Boletín de la Benemérita Sociedad de Geografía y Estadística de Jalisco. Capitulo Sur, II (v): 8-14. 
Vizcaíno, Juan (1991), "La fundación de Zapotlán el Grande”, Revista Estudios Jaliscienses, 5: 5-10, agosto.

Zanotelli, Francesco (2005), "La identidad del dinero. Rituales económicos en un pueblo mestizo de Jalisco", Relaciones, XXVI, (103): 53-91.

Zárate, José Eduardo (1997), Procesos de identidad y globalización económica. El Llano Grande en el sur de Jalisco, El Colegio de Michoacán, Zamora.

Zárate, José Eduardo (2003), "Recursos culturales e identidades locales en el sur de Jalisco", Estudios Jaliscienses, 53: 3650 , agosto.

Recibido: 7 de abril de 2006. Reenviado: 4 de octubre de 2006. Aprobado: 10 de noviembre de 2006.

Alejandro Macías Macías es doctor en ciencias sociales (especialidad en antropología social) por el Centro de Investigaciones y Estudios Superiores en Antropología Social (CIESAS-occidente); es miembro del Sistema Nacional de Investigadores y de la Benemérita Sociedad de Geografía y Estadística del Estado de Jalisco. Actualmente es profesor-investigador en el Centro Universitario del Sur de la Universidad de Guadalajara. Su línea de investigación se centra en los procesos de cambio socioeconómico regional. Entre sus más recientes publicaciones están: "Estrategias laborales de los empresarios hortícolas en México. El caso de Sayula, Jalisco", Cuadernos de Desarrollo Rural, 56, 24 páginas (2006); "Brillante pasado, difícil presente e incierto futuro en la economía del sur de Jalisco", Carta Económica Regional, 93, 22 páginas (2005); "Globalización, competitividad y cultura local”, Revista Digital Científica y Tecnológica e-Gnosis, 3, 24 páginas (disponible en < http://www.e-gnosis.udg.mx/vol3/art6>) (2005); "Crecimiento económico y competitividad de las regiones. Las ciudades medias de Jalisco: el caso de Zapotlán El Grande”, Región y Sociedad, XVI (31): 39-82 (2004). 